Old Dominion University

ODU Digital Commons

CCPO Publications

Center for Coastal Physical Oceanography

2012

\title{
The Rise and Fall of Crassostrea Virginica Oyster Reefs: The Role of Disease and Fishing in Their Demise and a Vignette on Their Management
}

Eric N. Powell

John M. Klinck

Old Dominion University, jklinck@odu.edu

Kathryn Ashton-Alcox

Eileen E. Hofmann

Old Dominion University, ehofmann@odu.edu

Jason Morson

Follow this and additional works at: https://digitalcommons.odu.edu/ccpo_pubs

Part of the Aquaculture and Fisheries Commons, Marine Biology Commons, and the Oceanography Commons

\section{Repository Citation}

Powell, Eric N.; Klinck, John M.; Ashton-Alcox, Kathryn; Hofmann, Eileen E.; and Morson, Jason, "The Rise and Fall of Crassostrea Virginica Oyster Reefs: The Role of Disease and Fishing in Their Demise and a Vignette on Their Management" (2012). CCPO

Publications. 71.

https://digitalcommons.odu.edu/ccpo_pubs/71

\section{Original Publication Citation}

Powell, E.N., Klinck, J.M., Ashton-Alcox, K., Hofmann, E.E., \& Morson, J. (2012). The rise and fall of Crassostrea virginica oyster reefs: The role of disease and fishing in their demise and a vignette on their management. Journal of Marine Research, 70(2-3), 505-558. doi: $10.1357 / 002224012802851878$ 


\title{
The rise and fall of Crassostrea virginica oyster reefs: The role of disease and fishing in their demise and a vignette on their management
}

\author{
by Eric N. Powell ${ }^{1,2}$, John M. Klinck ${ }^{3}$, Kathryn Ashton-Alcox ${ }^{1}$, Eileen E. Hofmann ${ }^{3}$ \\ and Jason Morson ${ }^{1}$
}

\begin{abstract}
We describe a model designed to simulate the shell carbonate budget of an oyster reef. We identify five parameters descriptive of basic characteristics of the shell carbonate budget of a reef that limit simulation accuracy. Two describe the TAZ (taphonomically-active zone) and the distribution of shell carbonate within it. One is the taphonomic rate in the TAZ. Two determine the volume contribution of shell carbonate and the taphonomic loss rate within the reef framework. For Mid-Atlantic estuaries, model simulations suggest that reef accretion only occurs if oyster abundance is near carrying capacity. Simulations further suggest that reef accretion is infeasible for any estuarine reach where dermo is a controlling influence on population dynamics. We forecast that the oyster disease dermo is a principal antagonist of reef persistence through its ability to limit shell addition.

Model simulations suggest that reefs with inadequate shell addition 'protect themselves' by limiting the volumetric content of shell carbonate in the TAZ. Thus, a dominant process is the transient expansion and contraction of the shell resource, otherwise termed cultch, within the TAZ, rarely expanding enough to generate reef accretion, yet rarely contracting enough to foster erosion of the reef framework. The loss of framework carbonate thusly is curtailed during periods when the surficial shell layer deteriorates. Stasis, a reef neither accreting nor eroding, is a preferred state. Reef recession requires an inordinately unbalanced shell carbonate budget. Results strongly argue for expanded focus on the dynamics of the shell resource within the TAZ, as this likely fosters a feedback loop with abundance through recruitment, serves as the protective layer for the reef during periods of reef stasis, and establishes the threshold conditions for reef accretion and recession. Model simulations suggest that attaining maximum sustainable yield and maintaining a biomass capable of supporting sufficient shell production for reef accretion are irreconcilable goals over a large component of the oyster's range. Reef stasis would appear to be the only achievable restoration goal in Mid-Atlantic estuarine reaches where dermo holds sway. Exploitation rates much above 5\% of the fishable stock per year restrict availability of surficial shell and foster reef erosion. In contrast, in the Gulf of Mexico at the high-productivity end of the oyster's range, an enhanced fishery and reef accretion may be compatible goals.
\end{abstract}

1. Rutgers University, Institute of Marine and Coastal Sciences and The New Jersey Agricultural Experiment Station, Haskin Shellfish Research Laboratory, Port Norris, New Jersey, 08349, U.S.A.

2. Corresponding author. email: eric@hsrl.rutgers.edu

3. Center for Coastal Physical Oceanography, Department of Ocean, Earth and Atmospheric Sciences, Old Dominion University, Norfolk, Virginia, 23508, U.S.A. 


\section{Introduction}

Once upon a time, East-coast and Gulf-coast estuaries were replete with oyster reefs (e.g., Moore, 1907, 1911; Powell et al., 1995a; Mann; 2000; Woods et al., 2005; Smith et al., 2005). They influenced, perhaps determined, such estuarine characteristics as phytoplankton content (Guyondet et al., 2005; Cerco and Noel, 2007), trophic food-web dynamics (Gottlieb and Schweighofer, 1996; Breitburg and Fulford, 2006; Coen et al., 2007), hydrodynamics (Lenihan, 1999), fetch (Newell and Koch, 2004), and characteristics of the salinity gradient (Galtsoff, 1931; Gunter, 1972). A large portion of these reefs have disappeared or are today in decline (Beck et al., 2009; but see Powell et al., 1995a; Power et al., 2010). Their loss stems from a host of reasons: shell dredging (Marshall, 1954; Woods et al., 2005; Powell et al., 1995a), overfishing (Rothschild et al., 1994; Jackson et al., 2001; Jordan and Coakley, 2004), and environmental change (Wilber, 1992; Powell et al., 1995a; Smith et al., 2005) being significant contributors, depending on local circumstances. A few of these processes involve physical removal of shell (e.g., shell dredging and, to a certain extent, harvest). Most, however, contribute to the lowering of abundance that ultimately results in a decline in the rate of shell addition to the reef.

Oyster shell is not a permanent resource (Powell et al., 2006; Mann et al., 2009). Rather, oyster shell suffers the vicissitudes of taphonomy poorly and, as a consequence, half-lives for oyster shell are typically no longer than decadal (Powell et al., 2006). Consequently, the addition of copious quantities of shell are required yearly to counterweigh the persistent loss of shell (Powell and Klinck, 2007; Mann et al., 2009). Over much of the world's oyster habitat today, shell loss very likely exceeds shell gain. This is certainly true for the larger East-coast estuaries of the U.S., Chesapeake Bay (Mann et al., 2009; Harding et al., 2010) and Delaware Bay (Powell and Klinck, 2007).

Not inconsequential in the demise of oyster populations in the Mid-Atlantic region of the U.S. is the impact of two diseases, MSX and dermo. Both depress abundance and, by shortening generation time (Mann et al., 2009; Powell et al., 2011c, this issue), also limit the quantity of shell added by the deaths they cause (Mann et al., 2009). The impacts of these two diseases on the oyster stocks is legendary (e.g., Andrews, 1979, 1988; Ford and Haskin, 1982; Ford, 1996, 1997; Ray, 1996). The impact on the oyster's habitat, the reef itself, has received minimal attention. However, the impermanence of oyster shell implies that shell production on oyster reefs may be a key determinant of the long-term continuity of the habitat and the oyster resource.

In this contribution, we first describe a model designed to simulate the shell carbonate budget of an oyster reef. Hereafter, we will use the term 'carbonate budget' to distinguish the reef budget that we model from the term 'shell budget' as applied to the surficial shell resource by previous authors (e.g., Powell and Klinck, 2007). We acknowledge the ambiguity that the term 'carbonate' entails, in that the term can be applied to the dissolved ion or used, as in this instance, as a shorthand for the calcium carbonate composite of the molluscan shell. The model we describe builds on earlier formulations by Powell et al. (2006) and Powell and Klinck (2007) and the creative applications by Mann et al. (2009) 
and Southworth et al. (2010). The model explicitly evaluates the carbonate budget for the surficial living reef, but also includes parameterization for the long-term accretion or erosion of the reef framework upon which the living reef rests. In proposing this model, we proffer a set of parameters that we posit are key regulators of this system. Following this, we apply a gene-based population dynamics model to examine the influence of dermo disease on the population and the reef, examining the impact of onset of the disease upon a naïve population and the subsequent fate of the population and the reef as the oyster attempts to adapt to the disease through the development of disease resistance. In doing this, we build on two previous examinations of this subject by Powell et al. (2011c, this issue). We next consider the influence of fishing, an activity postulated as causative for a substantial proportion of the demise of the oyster in some East-coast estuaries (Rothschild et al., 1994; Jordan et al., 2002; Jordan and Coakley, 2004; Woods et al., 2005). Finally, we reconsider the wisdom of reef restoration and shell-planting programs, building on previous discussions by Mann and Powell (2007) and Mann et al. (2009).

\section{Methods}

\section{a. Reef clumpiness}

Ruminations on reef clumpiness benefit from data obtained from stock surveys in Delaware Bay during 2005 to 2009. Survey design is detailed in Fegley et al. (2003) and Powell et al. (2008a). Clumps are defined as independent carbonate concretions, including single oysters, single shells, or single boxes, but often comprising aggregates of live oysters, shells, and/or boxes cemented into single conglomerates. As part of the survey protocol, the ten largest clumps were identified, each set on a flat surface as it may have sat on the bottom of the bay, and the longest length and height measured with digital calipers. As the orientation of the clump in situ was frequently ambiguous, following earlier conventions (e.g., Powell et al., 1987a, 1987b; Wilson et al., 1988) the two measurements were averaged for analyses to get a single clump dimension that was assumed to represent its vertical expression in situ.

\section{b. The reef carbonate-budget model}

i. Perspective. The reef carbonate-budget model divides the reef into two verticallyoriented components or tiers (Fig. 1). The surficial tier includes the living community and the surficial shell, typically termed cultch (Gunter 1938, 1972; Soniat et al., 1991; Bushek et al., 2004), both of which provide substrate for larval settlement. The subsurface tier is the compacted aggregated carbonate mass that represents the reef framework. The differentiation of the surficial tier from the subsurface tier is premised on the recognition that (a) shell is added only on the surface and (b) the taphonomic processes degrading carbonate proceed at a much higher rate on shell exposed at the sediment-water interface if for no other reason than the fact that boring bionts are most plentiful there. We define the TAZ (taphonomically-active zone - Davies et al., 1989) as synonymous with the surficial tier; 

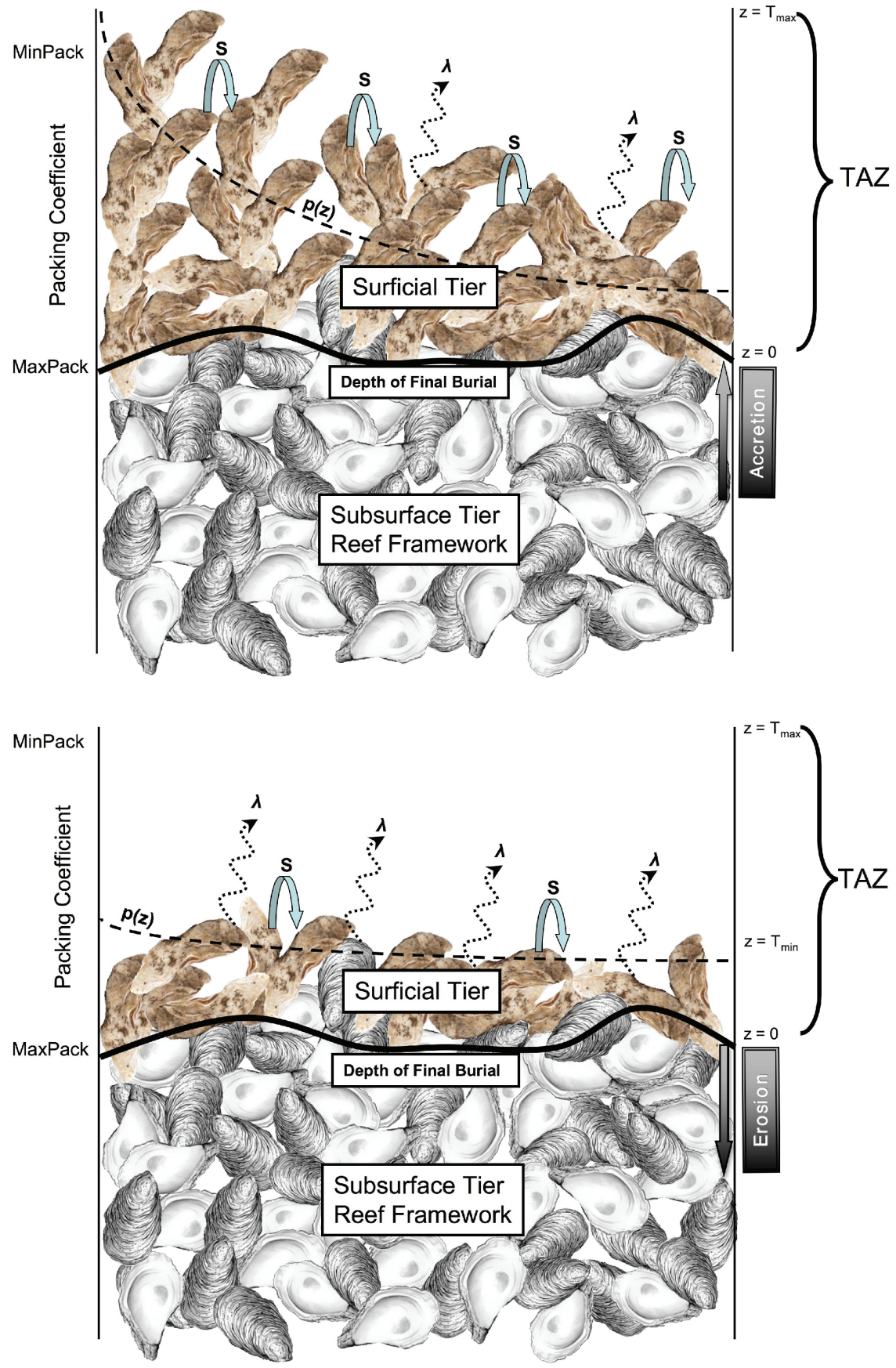

Figure 1. Stylized cross-section of an oyster reef in accretionary (above) and erosional (below) mode. On the left ordinate is the packing coefficient showing the relationship of $p(z)$ with its defined range between MaxPack and MinPack. On the right ordinate are the depth determinants in the TAZ, with $z=0$ marking the depth of final burial, dividing the surficial and subsurface tiers, and $z=T_{\max }$ marking the upper boundary of the TAZ. A third value, $z=T_{\min }$ on the lower depiction marks the 
thus, the TAZ is a zone that includes the live oysters, the surficial clumps and disaggregated shells, and no more than the upper few centimeters of the compacted reef. The boundary between the two tiers can be denoted the depth of final burial (DFB), although the finality of burial is determined over the long-term by the accretionary or recessionary status of the reef (Fig. 1).

The two tiers differ in a number of other ways. First, the porosity of the subsurface tier is assumed to be low and invariant with depth. In contrast, the surfacial tier has a complex vertical structure in which some fraction of the total carbonate is housed in clumps, shell, and live oysters that rise above the substrate surface (Moore, 1911; Powell and Ashton-Alcox, 2004; Powell et al., 2007; Stiner and Walters, 2008). The fraction of the volume occluded by shell declines with height above the bottom as the number of clumps of increasing size and vertical extent necessarily diminishes with increasing clump size. This structure establishes a zone of defined vertical extent wherein much of the shell is exposed to a range of taphonomic processes operating at a relatively rapid rate.

The two tiers interact. In an accreting reef, some carbonate becomes buried below the TAZ as carbonate addition exceeds loss, resulting in an incremental increase in reef framework thickness, ultimately yielding a geological mass rising above the surrounding soft sediment. In a degrading reef, as shell addition lags behind shell loss, some shell carbonate, once buried, becomes exposed ${ }^{4}$. The burial of shell below the TAZ is a common component of taphonomic models (Powell, 1992; Olszewski, 2004; Tomašových et al., 2006); the reverse, in which shell is re-exposed, though a well-known phenomenon in soft sediments (e.g., Aller, 1995; Powell and Davies, 1990; Best and Kidwell, 2000; Olszewski, 2004), has not routinely been modeled (Powell, 1992) and remains unconsidered in reef carbonate budgets. However, we know from direct observation that reefs can recede in height and that this recession is unexplained by regional sedimentation; indeed, loss of relief may occur commonly, and this requires erosion of the reef framework (e.g., Haven and Whitcomb, 1983; Woods et al., 2005; Mann et al., 2009).

ii. The surface tier (TAZ) - relationship of complexity, shell volume, and vertical relief. We define a vertical gradient in oyster shell density as the volume of shell occupying the total volume at any height above the DFB. This packing coefficient $P$ varies vertically within the surficial tier or TAZ such that the volume fraction occupied is highest at its base and lowest at the height of the highest routinely-encountered clump. The fraction of the TAZ volume occluded by shell is a nonlinear function of the maximum volume occupied by shell at the interface with the subsurface tier, the DFB, at a position defined as $z=0$ and the distance $z$ above the base of the TAZ. Thus,

$$
z=a(\text { MaxPack }-P)^{b}
$$

where $a$ and $b$ are shape parameters determining the relationship and MaxPack is the volume fraction occupied by carbonate at the base of the TAZ.

4. We distinguish the process of reef degradation from burial of the reef due to the accumulation of unconsolidated sediment at a rate exceeding the rate of reef accretion. 
Eq. (1) can be reorganized so that the vertical extent of the TAZ is described in terms of the differential between the packing coefficient at the base of the TAZ, MaxPack, and the packing coefficient at the apex of the TAZ, MinPack, where this apex is defined as the height above the bottom, $z=T_{\max }$, of the highest routinely-encountered oyster clump:

$$
T_{\max }=a(\text { MaxPack }- \text { MinPack })^{b} .
$$

From Eq. (2),

$$
a=\frac{T_{\max }}{(\text { MaxPack }- \text { MinPack })^{b}}
$$

which permits re-expression of Eq. (1) as

$$
z=T_{\max }\left(\frac{\text { MaxPack }-P}{\text { MaxPack }- \text { MinPack }}\right)^{b} .
$$

This relationship can be inverted to give

$$
P(z)=\text { MaxPack }-\left(\frac{z}{T_{\max }}\right)^{\frac{1}{b}}(\text { MaxPack }- \text { MinPack }) .
$$

Eq. (5) generates a hypothetical distribution of shell in the TAZ that can take a multitude of specific forms depending on the value of $b$ (Fig. 2). Note that most of these curves express an assumed nonlinear reduction in volume contributed by shell with height above the bottom such that shell rapidly becomes sparse over the first few $\mathrm{cm}$ of relief. This relationship will be considered more thoroughly in a later section.

The integral of Eq. (5) is the total mass of shell carbonate within the TAZ occupying a specified area of the bottom, stipulated by convention as $1 \mathrm{~m}^{2}$ hereafter. Thus, the total mass of shell carbonate, $M$ in $\mathrm{g} \mathrm{m}^{-2}$, is

$$
\begin{aligned}
M & =\rho_{c} \int_{z=0=D F B}^{T_{\max }} P(z) d z \\
& =\rho_{c} T_{\max }\left(\text { MaxPack }-\frac{b}{b+1}(\text { MaxPack }- \text { MinPack })\right)
\end{aligned}
$$

where $\rho_{c}$ is the density $\left(\mathrm{g} \mathrm{m}^{-3}\right)$ of oyster shell.

iii. The reef carbonate budget - surface and subsurface tier. A dynamic (time-dependent) carbonate-budget model for an oyster reef requires relationships for the surficial carbonate in the TAZ, $M_{T}$, and the buried carbonate below the DFB comprising the reef framework, $M_{F}$. Throughout, the subscript $T$ will be used for processes in the surficial tier or TAZ and the subscript $F$ for processes in the subsurface tier or reef framework. Each tier loses carbonate by taphonomic processes at rates defined by $\lambda_{T}$ and $\lambda_{F}$ (Fig. 1). Shell is transferred across the boundary between the TAZ and the reef framework based on the burial rate $\alpha_{T F}$ and the erosion rate $\alpha_{F T}$. In addition, a quantity of carbonate, $S$ (in $\mathrm{g} \mathrm{yr}^{-1}$ ), is added to the TAZ each 


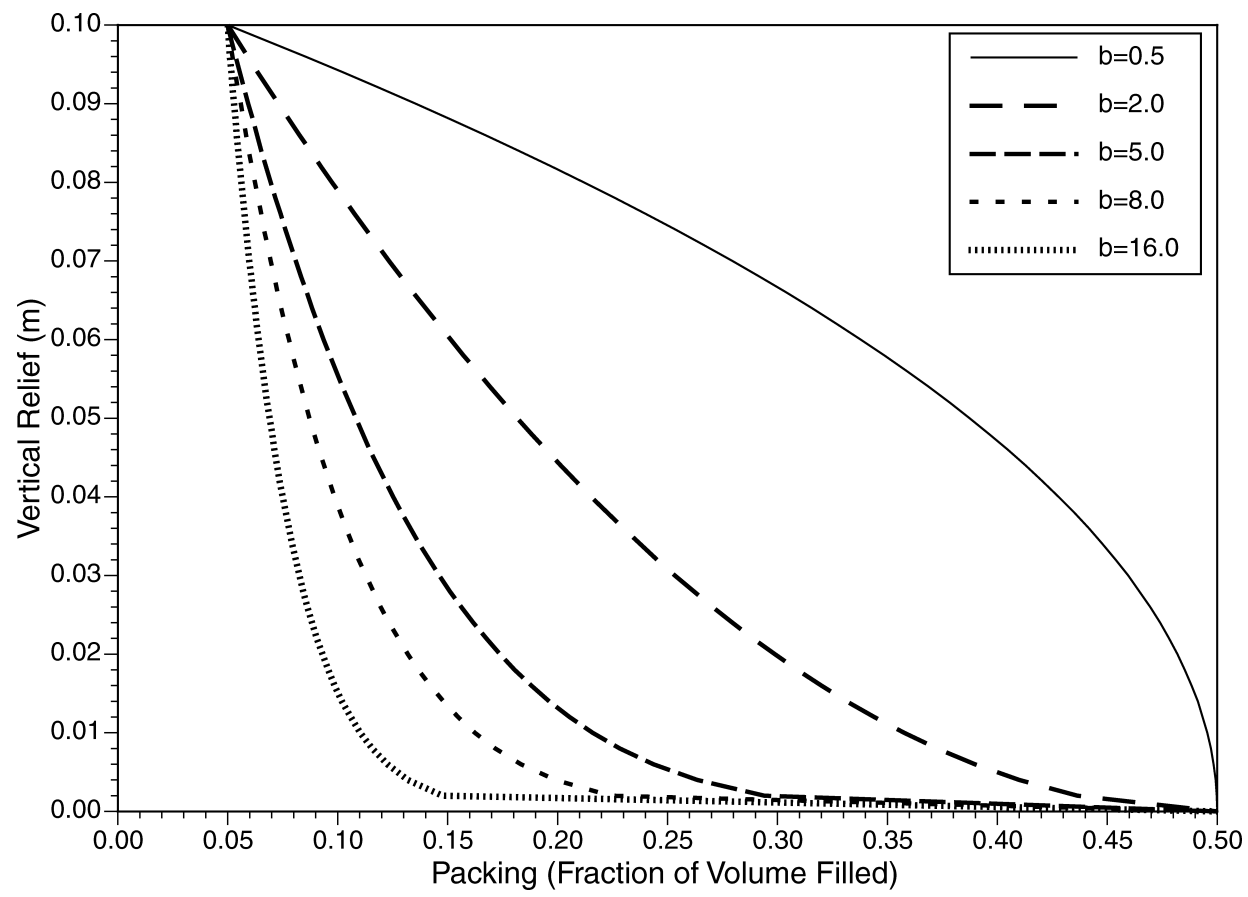

Figure 2. Fraction of volume occupied by carbonate as a function of position within the TAZ for five possible values of $b$, with $T_{\max }$, the height of the highest clump, set at $10 \mathrm{~cm}$.

year as determined by the number and size frequency of oysters dying. The relationship of oyster anterior-posterior length, $L$ in $\mathrm{mm}$, to shell mass, $S M$ in $\mathrm{g}$, is obtained from Powell and Klinck (2007):

$$
S M=0.00041 \times L^{2.70} ;
$$

thus,

$$
S=\sum_{i=1}^{d} S M_{i}
$$

where $d$ is the number of oysters dying each year.

The two relationships governing the addition to and loss of carbonate from the surficial (TAZ) and subsurface (reef framework) tiers are then:

$$
\frac{d M_{T}}{d t}=-\alpha_{T F} M_{T}+\alpha_{F T} M_{F}-\lambda_{T} M_{T}+S
$$

and

$$
\frac{d M_{F}}{d t}=\alpha_{T F} M_{T}-\alpha_{F T} M_{F}-\lambda_{F} M_{F}
$$


where the first term on the right-hand side is the transfer from the surface (TAZ) to the subsurface (reef framework) tier, the second term is the erosive movement of buried carbonate into the surficial tier, and the third term is the loss of shell by taphonomic processes. The fourth term in Eq. (9) is the addition of shell to the TAZ through the deaths of living oysters.

$i v$. The transfer rules - surface $\leftrightarrow$ subsurface. For the reef to grow, the subsurface framework must increase in thickness. This requires burial of carbonate beneath the TAZ [Eq. (10)]. However, if conditions change, and the reef enters a period of negative carbonate balance, the reef framework may begin to erode, moving buried carbonate back into the TAZ [Eq. (9)]. The model is based on two assumptions about the processes of accretion and erosion of the subsurface tier. First, these processes are determined by the distribution of carbonate in the TAZ; healthy growing reefs have a degree of vertical complexity due to the growth of oyster clumps and the filling of voids between clumps by disarticulating shells (Fig. 1). Thus, only vertically complex reefs accrete. Second, when the carbonate balance is negative, the movement of carbonate back into the TAZ is inhibited by the limited porosity at the exposed surface. Erosion does not create vertical complexity. Thus, most of the vertical complexity must be lost before the erosive transfer of buried carbonate back into the TAZ becomes significant.

Accordingly, burial occurs when the exposed reef exceeds a certain height $T_{\max }$. Burial rate increases as the clumps of the living reef increasingly surpass $T_{\max }$ in height. This is equivalent, from Eq. (6), to the volume fraction of carbonate exceeding the amount that can accumulate in the TAZ before the rate of clump disaggregation and shell accumulation at its base begins to bury shell and as a consequence re-establishes the initial volume fraction and dimension, $T_{\max }$. In the figures that follow, the amount of shell in the TAZ will be portrayed in terms of clump height $T$ recognizing that variation in this variable is equivalent to variation in the volume fraction of carbonate in the TAZ.

If the vertical expression of the living reef, the TAZ, is less than $T_{\max }$, then some part of the buried reef may become exposed through erosive processes; carbonate is transfered into the TAZ. However, the rate of mobilization of buried carbonate is presumed to be low over a large range of surficial complexity. In anthropomorphic terms, the reef protects itself by limiting the exposure of framework carbonate to taphonomic processes during periods of negative carbonate balance by exposing a relatively flat surface to the overlying water. Thus, when the surficial carbonate declines to a low level and perforce a very low relief, the reef expresses a vertically narrow TAZ defined as $T<T_{\min }$. Only at this point is buried carbonate exposed relatively rapidly and thus transferred into the TAZ.

These processes are summarized as follows. For $T<T_{\max }$, the maximum-height of routinely-encountered clumps $T$ is too low to provide sufficient carbonate coverage in the TAZ to promote burial. Erosion may occur depending upon the relationship of $T$ to $T_{\min }$ :

$$
\alpha_{T F}=0
$$


and

$$
\alpha_{F T}=\left(\alpha_{\max _{F}}\left(1-\tanh \left(\frac{T-T_{\min }}{\alpha_{\text {slope }_{F}}}\right)\right)\right)+\left(\alpha_{\min _{F}}\left(T_{\max }-T\right)\right) .
$$

For $T>T_{\max }$, the height of routinely-encountered oyster clumps exceeds $T_{\max }$ and reef accretion occurs at a rate determined by the exceedance of $T$ over $T_{\max }$ :

$$
\alpha_{T F}=\alpha_{\max _{T}}\left(1-\tanh \left(\frac{\left(\beta_{T} T_{\text {max }}\right)-T}{\alpha_{\text {slope }_{T}}}\right)\right)
$$

and

$$
\alpha_{F T}=0 .
$$

\section{c. DyPoGEn (Dynamic Population Genetics Engine)}

i. Overview. Simulations from a gene-based population dynamics model are used to provide a time series of shell addition [S in Eq. (9)]. See Powell et al. (2011a,c) for a full description of DyPoGEn. The model simulates a population composed of multiple cohorts, each composed of multiple individuals and can be described as the marriage of three components: a post-settlement population dynamics submodel that contains parameterizations for growth, mortality, and reproduction; a larval submodel that contains parameterizations for larval mortality; and a gene submodel that describes each animal in terms of its genetic structure and that tracks genotype through time from one cohort to the next. Finally, a genotype-phenotype interface interprets genotype in terms of fitness that then influences the larval and post-settlement submodels. This permits the feedback between genotype and phenotype that drives selection.

Powell et al. (2011c, this issue) describe the model structure for reproduction, sex change, and larval mortality. Very briefly, each simulated mating season creates a new generation represented by a cohort of newly-recruited individuals. Most simulations supporting this study were conducted under the assumption that animals born in one year do not spawn in the same year, a reproductive pattern typical of all but the most southern climes (Stauber, 1950; Hayes and Menzel, 1981; Kennedy and Krantz, 1982; Barber et al., 1991). Each year, the population first suffers adult mortality at a rate that is age-dependent [see Powell et al. (2011c, this issue) for justification; see also Martinius (1991)]. The age of all individuals in the population is incremented by one and the functional sex changes for some individuals. Then reproduction occurs with gametes formed through the process of meiosis such that each set of haploid chromosomes is obtained as a random draw from the parental genotype. The fate of each offspring is controlled by random larval mortality at a rate set to permit establishment of a relatively stable population; thus, a compensatory broodstock-recruitment relationship is assumed (Powell et al., 2009a). 
In the following subsections, we provide additional details focused solely on the components controlling mortality and fitness based on the presence of alleles conferring disease resistance. The reason for this focus is the later simulation of reef carbonate budgets for populations influenced by dermo disease and the potential response of the population through the development of disease resistance that might result, ultimately, in a diminishing impact of dermo on shell production.

ii. Mortality. Although juvenile mortality is high in bivalves, this portion of mortality was subsumed into larval mortality, as the purpose of the simulations was to examine the influence of mortality factors acting on sexually mature animals that dominate shell production. Thus, an age-dependent adult mortality rate was imposed by deriving the probability of dying from the age of the animal according to the formulae:

$$
\begin{gathered}
A M=\text { AvgAgeMort }-((1-\text { FitFac }) \cdot d \text { AvgAgeMort }) \\
\text { ASM = AvgSpreadMort }-((1-\text { FitFac }) \cdot d \text { AvgSspreadMort }) \\
\operatorname{Pr}=.5\left[1+\tanh \left(\frac{\text { Age }- \text { AM }}{A S M}\right)\right]
\end{gathered}
$$

where $\mathrm{Pr}$ is the probability of dying, AvgAgeMort is the average age of mortality ( $\mathrm{Pr}$ is 0.5 at this age), and Avg SpreadMort controls how rapidly the mortality approaches 1 . Fit Fac is a fitness factor that varies mortality by reducing the average age of death by the factors $d A v g$ AgeMort and $d$ Avg SpreadMort.

Dermo-induced mortality is modulated by the local environment, particularly the late summer temperature and salinity (Andrews, 1988; Powell et al., 1996; Ragone Calvo et al., 2001). Thus, we considered two levels of mortality at the onset of disease, interpretable as relative measures of the virulence of the disease or conduciveness of the environment: $\sim 40 \%$ of the population yearly and $\sim 22 \%$. The lower rate is representative of epizootic mortality rates often observed in Delaware Bay and Chesapeake Bay (Burreson and Ragone Calvo, 1996; Powell et al., 2008a, 2009a). The higher rate is a minimal value for the Gulf of Mexico (Mackin, 1959, 1962; Mackin and Sparks, 1962; Mackin and Hopkins, 1962) and a level observed in the initial epizootics after onset of dermo disease in the higher-mortality regions of Delaware Bay (Powell et al., 2008a, 2009a).

iii. Genetic structure and implementation of fitness. The genetic structure of each oyster is defined in terms of 10 pairs of chromosomes (Wang et al., 1999, 2005), each in the present study with four genes and two alleles. Thus the genotypes permitted for each locus were $A A$, $A B$, and $B B$. Guo (unpubl. data) identified fourteen loci distributed among the majority of the chromosomes (see Table 1 in Powell et al., 2011c) with alleles that may confer some degree of disease resistance to mortality from dermo disease. Most models of geneticallybased disease resistance rely on one-locus (e.g., Wilhoit, 1991; MacKenzie and Bishop, 1999; Abell et al., 2005) or two-loci (e.g., Galvani and Slatkin, 2004) configurations. For dermo disease, a multi-locus model is required (Powell et al., 2011c). The initially-low allele frequency for alleles conferring disease resistance, approximately $10 \%$, invoked the 


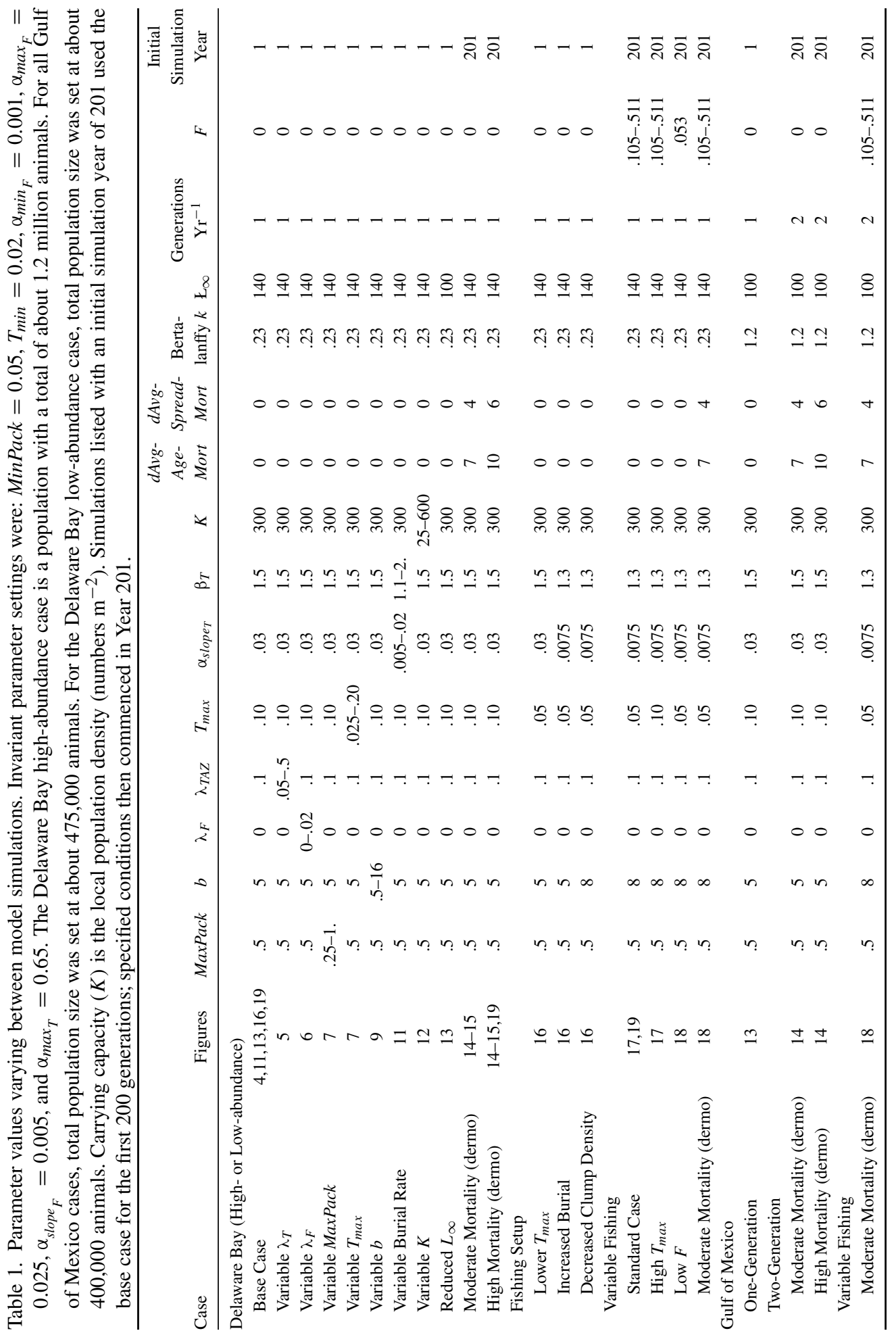


assumption that such alleles are rare in naïve populations, possibly due to the likelihood that such alleles are inherently deleterious if the disease is not present (e.g., Cotter et al., 2004; Zbinden et al., 2008; Hasu et al., 2009; Duffy and Forde, 2009). Most oyster loci have more than two alleles (Launey and Hedgecock, 2001; Wang and Guo, 2007). For these simulations, we assume that only one of these alleles is associated with disease resistance, so that a two-allele configuration can be used with the second allele representing the host of alleles having no influence on disease resistance.

Fitness is the mechanism by which physiological function is encoded by the genes. The relative contribution of each of the permitted genotypes, $A A, A B$, or $B B$, to disease resistance is independently set so that one locus may be characterized by dominance and another overdominance, for example. Fitness for an individual is determined as the average of the fourteen values determined for each of the fourteen loci conferring disease resistance standardized to fall within a range of 0 for completely susceptible to 1 for fully resistant, inclusive. In simulations reported here, the survival of the adult animal is affected by a fitness value, FitFac, as specified in Eqs. (15) and (16). Each simulation is referenced against a base case configured for a mortality rate thought to be characteristic of oyster populations before the onset of significant mortality by dermo disease. This value is $10 \%$ to $15 \%$ of the adult population per year (Powell et al., 2008, 2009a). Dermo disease is introduced by

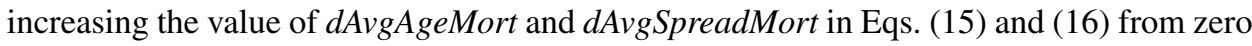
to some value between 0 and the respective values of AvgAgeMort and AvgSpreadMort. This increases the rate of adult mortality to the degree permitted by the fitness value of the individual as determined by FitFac. An example is shown in Figure 3 in which a naïve population with a yearly mortality of about $13 \%$ of the stock without the disease (labeled $\mathrm{F}=1$ in Fig. 3 ) is exposed to a yearly mortality of about $24 \%$ of the stock at FitFac $=0$ (labeled $\mathrm{F}=0$ in Fig. 3). After developing complete resistance to the disease at FitFac $=1$, the stock attains the natural mortality rate of the unexposed naïve population (labeled $\mathrm{F}=1$ in Fig. 3).

\section{Oyster-reef carbonate-budget model: Formula appraisal and parameter valuation}

\section{a. Perspective}

The sobering apprehension under which this modeling exercise proceeds is the exceedingly limited understanding of the mechanisms of oyster reef formation in comparison to the vast quantity of research on the oyster itself. Oysters are the reef builders of the temperate zone, far outstripping the works of other creators of hard bottom at these latitudes, such as serpulid and sabellariid polychaetes. Yet, little beyond the description of Wreck Shoals by DeAlteris (1988) and some descriptions of fossil reefs (e.g., Parras and Casadío, 2006; Pufahl and James, 2006) is known about the geological structure and mode of construction and consolidation of this most important component of the estuary. The consequence of this abysmal paucity of information is to emplace severe constraints on model construction and 


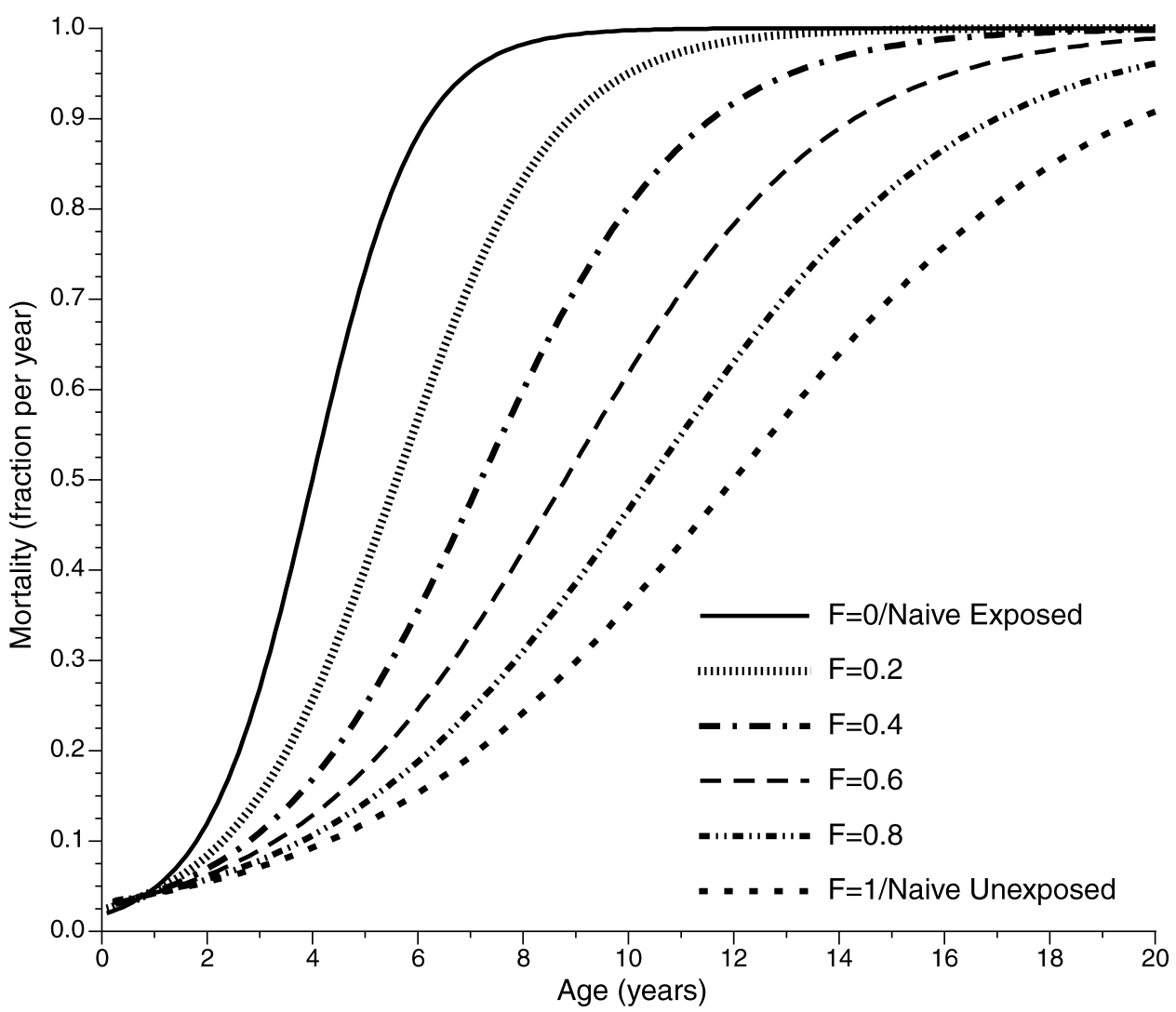

Figure 3. An example of oyster mortality trends with age while fitness varies by 0.2 units from a fitness of 0 to a fitness of 1 . The fitness-of -0 case $(F=0$ or naïve exposed) yields a population mortality rate of about $24 \%$. The fitness-of- 1 case $(\mathrm{F}=1$ or naïve unexposed $)$ yields a population mortality rate of about $13 \%$.

severe limitations on model verification. Persevering under these encumbrances, we propose a general model for the mechanics of reef construction and destruction as a hypothesis rather than a synthesis of knowledge. In accordance with this proposition, we first discuss thoroughly the rationale for the parameterizations chosen and, for a selection of them, we evaluate the influence of a range of values upon model performance. Our initial foray is based on the thorough discussion of Mann et al. (2009) that can be summarized for our purposes thusly. Over geological time, oyster reefs increment slowly as their long-term average accretion rate cannot exceed the rate of sea level rise. Thus, carbonate production must be only marginally more rapid than carbonate loss even on healthy and accreting reefs most of the time. Occasionally, higher rates may occur (e.g., DeAlteris, 1988; Powell et al., 1995a), but such time periods must be of limited duration. 


\section{b. Base case parameterization}

Figure 4 shows an accreting reef for which shell input consistently exceeds loss. In this simulation, the amount of added shell varies over time as population abundance rises and falls about a carrying capacity of about 300 animals $\mathrm{m}^{-2}$. Over the course of 200 years, the subsurface tier increments in elevation by almost $30 \mathrm{~cm}$, a rate consistent with DeAlteris' (1988) estimates for Wreck Shoals during its phase of rapid growth. For much of the time, the vertical relief of the surficial tier, the living reef, varies from 10 to $11 \mathrm{~cm}$. Excursions above $11 \mathrm{~cm}$ are rare because burial occurs whenever the TAZ exceeds $10 \mathrm{~cm}$ in thickness, as it does throughout much of this simulation.

The simulation shown in Figure 4 is based on a Delaware Bay simulation (High Abundance Base Case, Fig. 8 in Powell et al., this issue) of an undiseased (thus unexposed or naïve) oyster population near carrying capacity existing under a natural mortality rate of about 10 $13 \%$ per year. Such populations have a few animals reaching nearly 20 years of age and a robust size frequency that includes numerous large animals (von-Bertalanffy $L_{\infty}=140 \mathrm{~mm}$; Kraeuter et al., 2007). We have only limited knowledge of the population characteristics of unfished reefs pre-disease in Mid-Atlantic estuaries, all anecdotal. Literature accounts frequently reveal abundances of 250-350 oysters $\mathrm{m}^{-2}$. Oyster density in the mid-1970s high-productivity regime in Delaware Bay is estimated to have been near carrying capacity, in the range of 200-300 $\mathrm{m}^{-2}$ (e.g., Powell et al., 2008a). These values resulted in estimated limitations on growth due to local competitive interactions limiting food supply based on the simple flux model of Wilson-Ormond et al. (1997). Population dynamics modeling indicates that abundances considerably exceeding this density surpass carrying capacity at rational levels of food supply (e.g., Powell et al., 1995b; 2009b; Wilson-Ormond et al., 1997).

Consequently, the simulated population in Figure 4 is designed to be representative of 1970s conditions in Delaware Bay and illustrative of the population dynamics of the best example in the Mid-Atlantic region of a relatively unimpacted population surveyed with modern random-sample survey methods; thus Figure 4 should be at least reminiscent of pristine conditions. Note in particular that a fishing mortality rate that exceeded $4.4 \%$ of the entire stock per year occurred in only one year in Delaware Bay during this period (Powell et al., 2008a). The simulation was conducted under the following important additional assumptions: (1) the packing coefficient (MaxPack) is 50\% with a minimal value $10 \mathrm{~cm}$ above the reef surface $\left(T_{\max }\right)$ of $5 \%$; (2) significant reef accretion occurs only when the volume of shell in the TAZ results in a vertical relief of the living reef exceeding $10 \mathrm{~cm}$; (3) mobilization of the underlying buried reef increases rapidly only when the surficial reef has degraded to a relief of $2 \mathrm{~cm}\left(T_{\min }\right)$; (4) the taphonomic loss rate for buried carbonate $\left(\lambda_{F}\right)$ is negligible; and (5) the taphonomic rate in the TAZ $\left(\lambda_{T}\right)$ is equivalent to a 10-year half-life for added shell. Parameter values are given in Table 1.

\section{c. Parameterization and uncertainty}

i. Preliminaries. Recognizing the limited database from which to develop a model for the process of reef accretion, we now consider the sensitivity of the outcome depicted in 

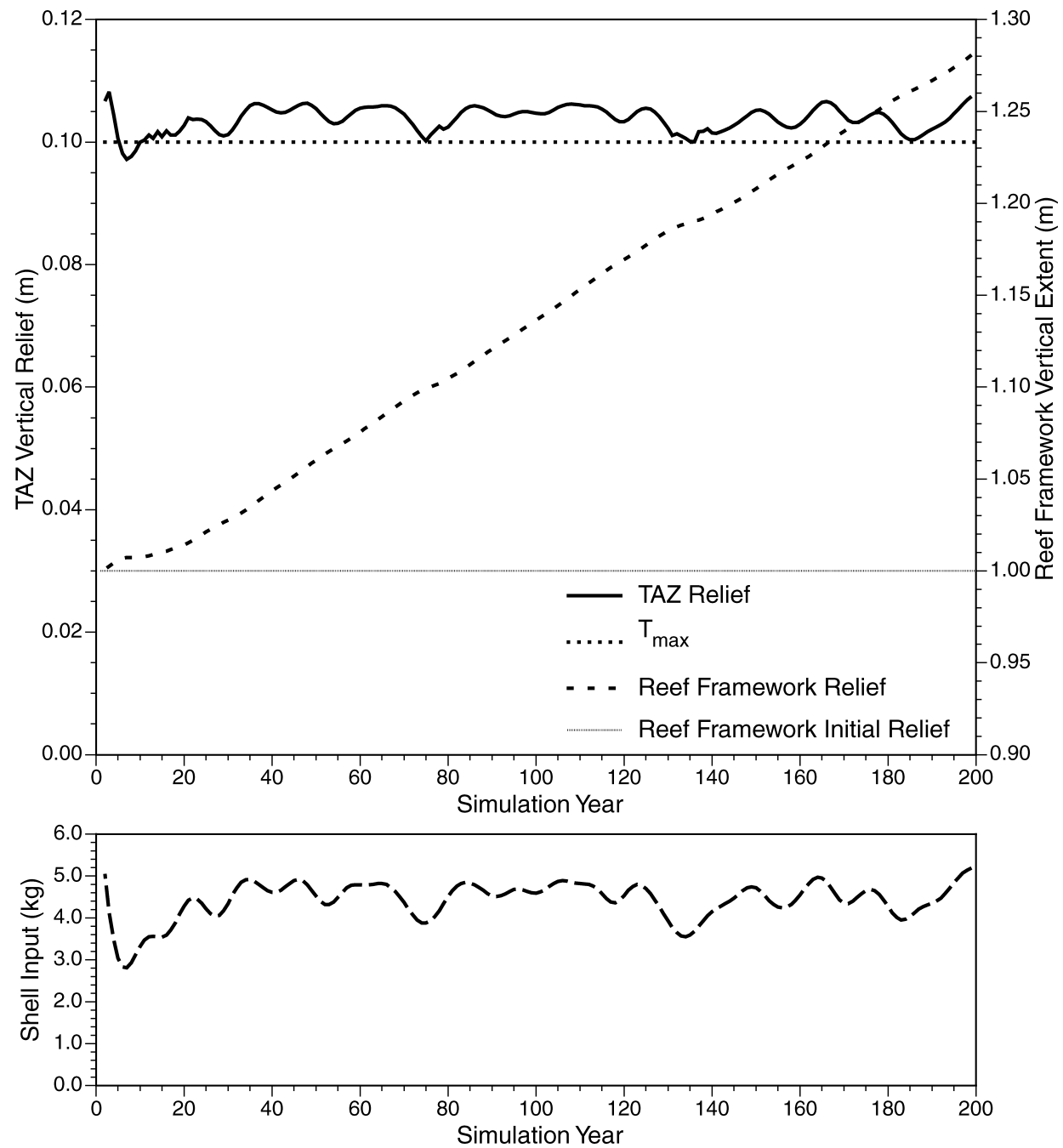

Figure 4. Temporal history of surficial (TAZ) and subsurface reef carbonate for a simulated oyster reef in Delaware Bay prior to the onset of MSX or dermo disease, and in the absence of fishing [see Table 1 for details; additional information on this simulation can be found in Figure 8 of Powell et al., this issue.] Above: The vertical extent of the TAZ over 200 years relative to the threshold eliciting burial of shell $\left(T_{\max }=10 \mathrm{~cm}\right)$ and the relief of the reef framework relative to the $1-\mathrm{m}$ relief defined at the initiation of the simulation. Below: The amount of shell added each year per $\mathrm{m}^{2}$ through deaths of living oysters.

Figure 4 to variations in a selection of the basic parameters controlling the taphonomic rates, burial rates, and structure of the living and buried reef. We impose a few constraints. From Mann et al. (2009), we anticipate that accretion will occur under only a very few conditions whereas stasis or degradation will occur over a wide range of conditions. From 
DeAlteris (1988), we assume that rapid accretion rates are possible, but from Mann et al. (2009), we expect to find that such rates occur under an exceedingly limited set of optimal conditions and, in fact, we observe that rapid accretion of reef has been documented very rarely (e.g., Powell et al., 1995a; Power et al., 2010). The model requires that the following parameters be set: $\lambda_{F}, \lambda_{T}$, MaxPack, MinPack, $b, T_{\max }, T_{\min }, \alpha_{\max _{F}}, \alpha_{\min _{F}}, \alpha_{\text {slope }_{F}}, \alpha_{\max _{T}}$, $\alpha_{\text {slope }}, \beta_{T}$, and $\rho_{c}$. The model also requires input of carbonate as a time series: $S(t)$. We consider parameterization of each of these in the following sections.

ii. Oyster shell density. Oyster shell is primarily calcitic, but the density, $\rho_{c}$, is somewhat less than that of pure calcite, due to the presence of voids, chalky layers, a foliated microstructure, and the organic matrix (Kennedy et al., 1969; Rosenberg, 1980; Carriker et al., 1980; Hong et al., 1995). Estimates of oyster shell density vary in the range of 2.2-2.5 $\mathrm{g} \mathrm{cm}^{-3}$ (Taylor and Layman, 1972; Nell et al., 1999; Yoon et al., 2004; Powell and Klinck, 2007). We use the value of $2.2 \mathrm{~g} \mathrm{~cm}^{-3}$.

iii. Taphonomic loss: $\lambda_{F}, \lambda_{T}$. Oyster shell breaks down relatively quickly in comparison to most molluscan shell other than mytilid mussels [compare Powell et al. (2006) to e.g., Peterson (1976), Callender et al. (1994), Strayer and Malcom (2007); Powell et al. (2008b); Kosnik et al. (2009)]. Half-lives estimated from reefs in Delaware Bay varied between $<5$ and 20 years with most $<10$ years (Powell et al., 2006). Mann et al. (2009) inferred similar rates for Chesapeake Bay and Waldbusser et al. (2011) observed similar rates under experimental conditions. We assume that these estimates are TAZ rates; that is, the component of shell sampled by survey methods is a good representation of the shell within the TAZ.

Why oyster shell degrades so rapidly is unclear [but see Taylor and Layman (1972) for data on compressive strength], although bioerosion as well as dissolution is certainly at work (Warburton, 1958; Gunter et al., 1957; Carriker et al., 1980). Bioerosion rates are well documented in some tropical and temperate habitats (Powell et al., 1989; Sartoretto, 1998; Lescinsky et al., 2002; Wisshak et al., 2005; Mallela and Perry, 2007), but measured rates for oyster shell are few (Carver et al., 2010), although bioerosion is assumed to be an important mechanisms of shell loss (e.g., Warburton, 1958; Bahr and Lanier, 1981; Carriker et al., 1980). Dissolution is a principal taphonomic process in most estuarine and marine habitats (e.g., Staff and Powell, 1990; Cutler, 1995; Walker and Goldstein, 1999; Lazo, 2004; Villiers, 2005); the details of the process and the degree of modulation by microbiota versus geochemistry are poorly understood (Powell et al., 2008b, 2011b, 2011d). Fragmentation by biotic attack is also a common occurrence (e.g., Lawrence, 1968; Elner and Lavoie, 1983; Zuschin et al., 2003), and, although this does not result in the loss of carbonate, the change in particle size very likely influences the rate of further degradation (e.g., Cummins et al., 1986; Kidwell, 2001). Nevertheless, the apparently more rapid loss of oyster shell relative to other estuarine shell resources conforms to the tendency for shell exposed on hard grounds and carbonate-rich sediments to be much more rapidly degraded than shell exposed on or buried in siliciclastic sediments (Powell et al., 2008b, 2011b; Best et al., 2007; Best, 2008). 

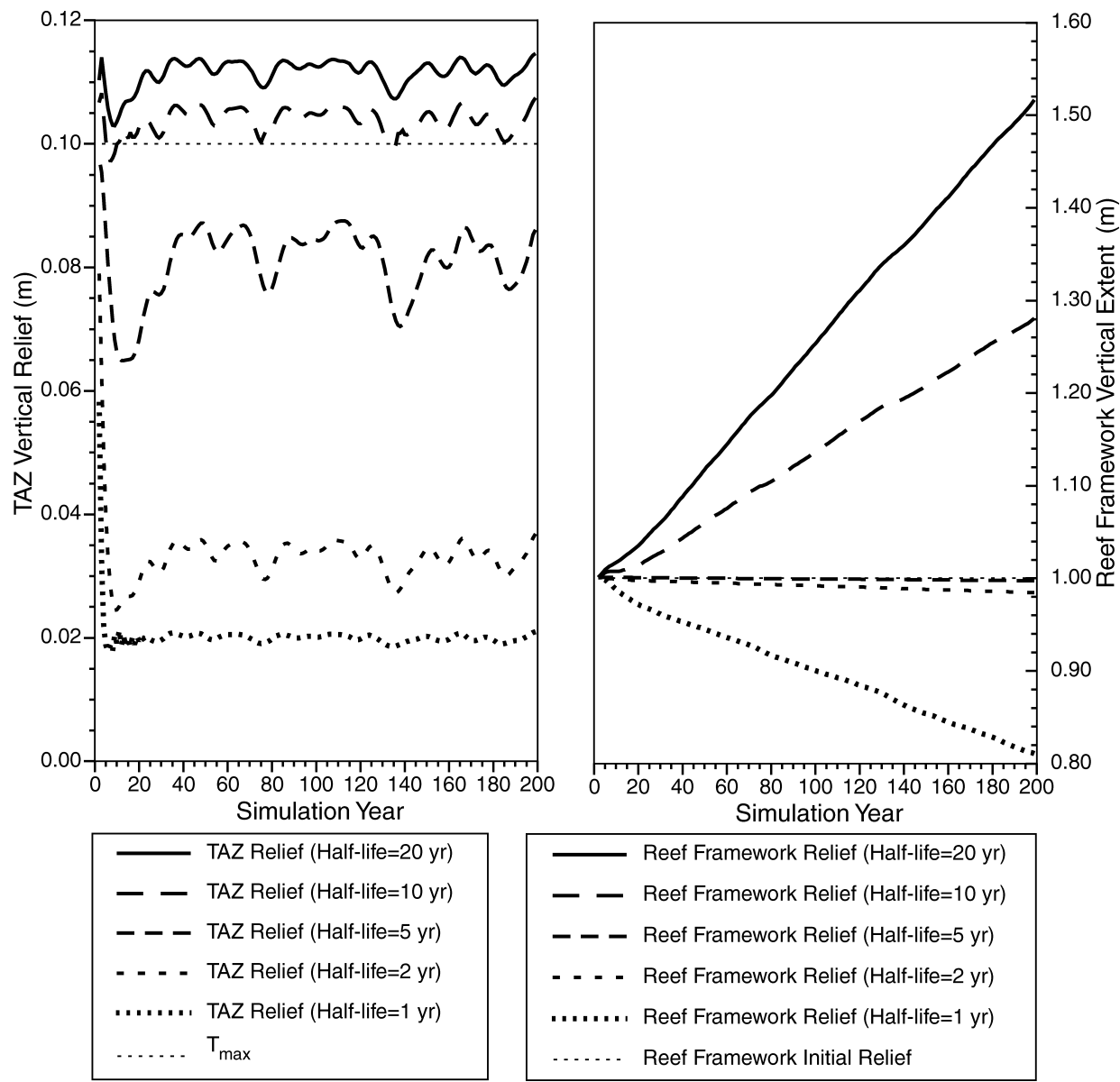

Figure 5. Temporal history of surficial (TAZ) and subsurface reef carbonate for a simulated oyster reef derived from the base case for Delaware Bay depicted in Figure 4 (see Table 1 for additional details) under five assumed values for $\lambda_{T}$, the taphonomic loss rate for shell within the TAZ. Left, the vertical extent of the TAZ over 200 years relative to the threshold eliciting burial of shell $\left(T_{\max }=10 \mathrm{~cm}\right)$. Right, the relief of the reef framework relative to the $1-\mathrm{m}$ relief defined at the initiation of the simulation.

Simulations with a range of $\lambda_{T}$ consistent with half-lives reported from Delaware Bay (Powell et al., 2006) reveal that half-lives much shorter than 10 years produce reef stasis ${ }^{5}$ or degradation (Fig. 5). Shorter half-lives of two to five years result in less surficial shell, even though the reef framework remains relatively unaffected, consistent with observation

5. Stasis as used here will refer to a reef neither rapidly accreting nor rapidly eroding with a change in relief of no more than $0.1-0.2 \mathrm{~m}$ over a period of several hundred simulation years. 
(Powell et al., 2006). Longer half-lives promote reef accretion. Thus field-estimated halflives and measures of the shell budget in the TAZ (Powell and Klinck, 2007; HSRL, 2010) are consistent with model expectation (Fig. 5). Results are also consistent with the calculations of Mann et al. (2009) and observations of DeAlteris (1988).

In most simulations, we assume a 10-year half-life, a value permitting reef accretion for populations near carrying capacity. Eq. (9) assumes that all carbonate is equally susceptible to degradation within the TAZ, ignoring particle size-dependent processes that may be important. Variations in surface-to-volume ratio, the possibility that borers may be more active in larger shells, and the fact that shell amalgamated into clumps may expose more surface area than shell reclining on the bottom are potentially important modulators of carbonate loss. No information is available permitting inclusion of these complexities in the model.

Whether buried reef retains carbonate without loss is unknown. Any packing coefficient less than $100 \%$ would suggest some interstitial flow that might result in slow carbonate loss. Certainly, the rate of degradation of carbonate within the reef framework below the DFB is much lower than in the surficial tier; that is, half-lives are much longer. Carbonate degradation is an ongoing process in carbonate soft sediments (e.g., Powell et al., 1989; Walter and Burton, 1990; Hover et al., 2001; Parsons-Hubbard, 2005; Perry and Taylor, 2006) and water flow through coral reefs and carbonate sands is well-described (Tribble et al., 1992; Jones et al., 2009; Burdige et al., 2010; see also Precht and Huettel, 2004), but the degree of permanence of carbonate encased within the oyster reef framework is unknown. Simulations suggest that half-lives of 500 years or less for buried shell produce some reef degradation, with shorter half-lives resulting in rapid reef recession (Fig. 6); thus, the expectation that loss of carbonate from buried reef is negligible seems a necessary conclusion. This outcome is consistent with the general view that the base of the TAZ, the depth-of-final-burial, demarcates a horizon below which carbonate loss is exceedingly slow (Powell, 1992; Olszewski, 2004) and with observations by Waldbusser et al. (2011) that previously buried shell is less taphonomically active than recently-dead shell. By inference, half-lives must be at least 50 to 100 times longer for buried shell than for surficial shell. Hereafter, we assume that taphonomic loss ceases below the DFB: that is, $\lambda_{F} \sim 0$.

iv. Packing coefficients for carbonate - MaxPack, MinPack. The volume of carbonate per volume of reef is set by MaxPack [Eq. (5)]. DeAlteris (1988) estimates a porosity of 50\%, a value used by Mann et al. (2009) [compare Dorshel et al (2007) for coldwater carbonate mounds]. Whether this value is representative is unknown as is the material that might fill the interstices wherever voids do not exist [see Perry and Smithers (2006) for an analogy], although the fill likely includes considerable siliciclastic material (Twichell et al., 2010). As a consequence, we investigate a range of packing coefficients from $25 \%$ carbonate to $100 \%$ carbonate (Fig. 7). MinPack is set to 0.05 at some height above the bottom consistent with the height of the highest routinely-encountered oyster clumps. 


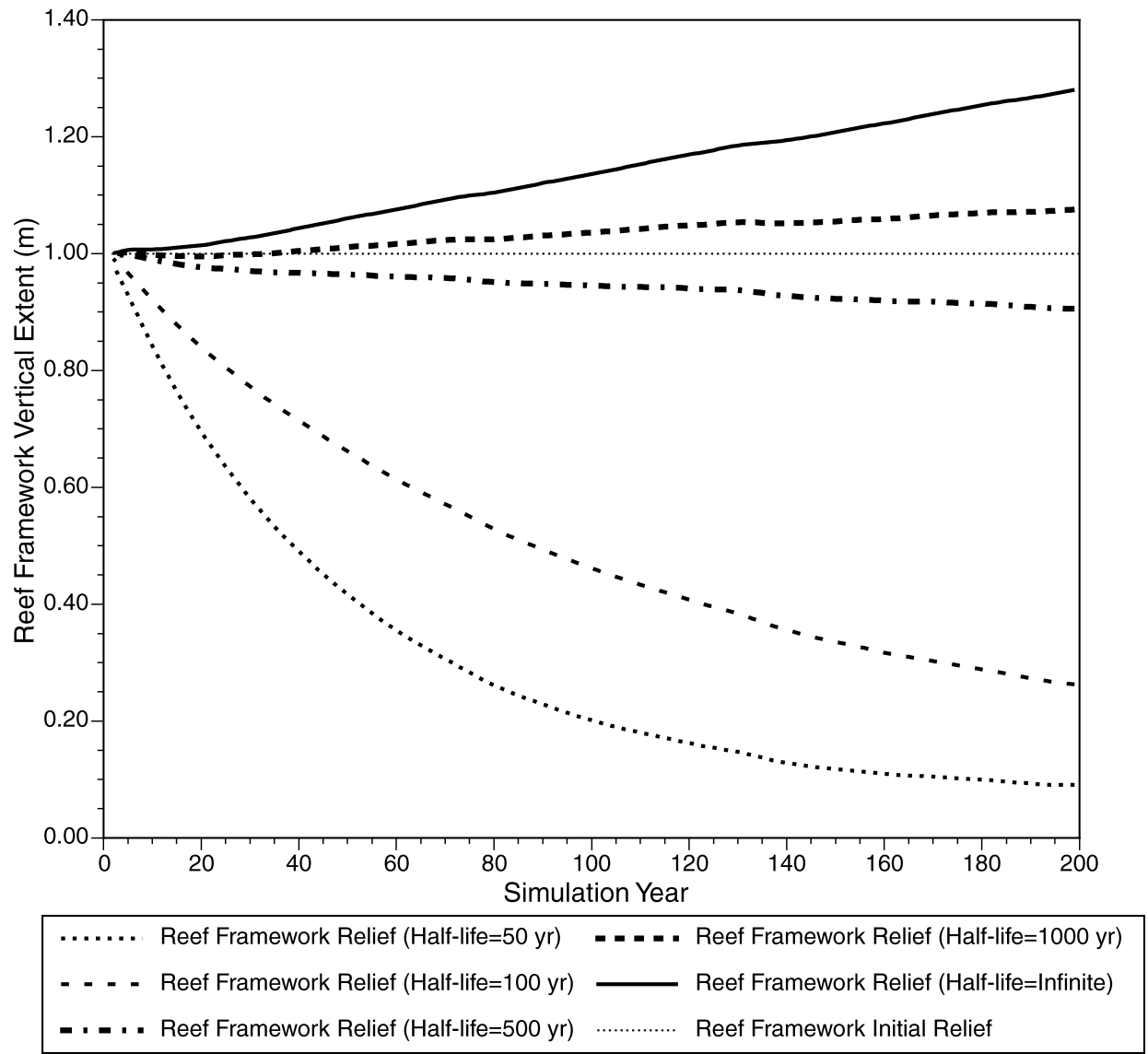

Figure 6. Temporal history of subsurface reef carbonate for simulated oyster reefs derived from the base case for Delaware Bay depicted in Figure 4 (see Table 1 for additional details) under four assumed values for $\lambda_{F}$, the taphonomic loss rate for shell below the DFB. Depicted is the relief of the reef framework relative to the $1-\mathrm{m}$ relief defined at the initiation of the simulation.

Simulations suggest that little reef accretion occurs if the reef framework is $75 \%$ to $100 \%$ carbonate (Fig. 8). As the contribution of carbonate to reef framework volume declines below $75 \%$, the rate of reef accretion accelerates. We suspect, however, that packing coefficients much less than 50\% imply the existence of substantial fine material that would smother live oysters (e.g., Moore, 1911; Lenihan, 1999; Smith et al., 2001). We note, in contrast, that Allen (1974) suggests that packing coefficients of 10-20\% may be stable configurations for shell beds. Regardless, the simulations suggest that the packing coefficient is a key variable controlling reef accretion and recession and provides some support for accepting the DeAlteris (1988) estimate as consistent with reef growth. 

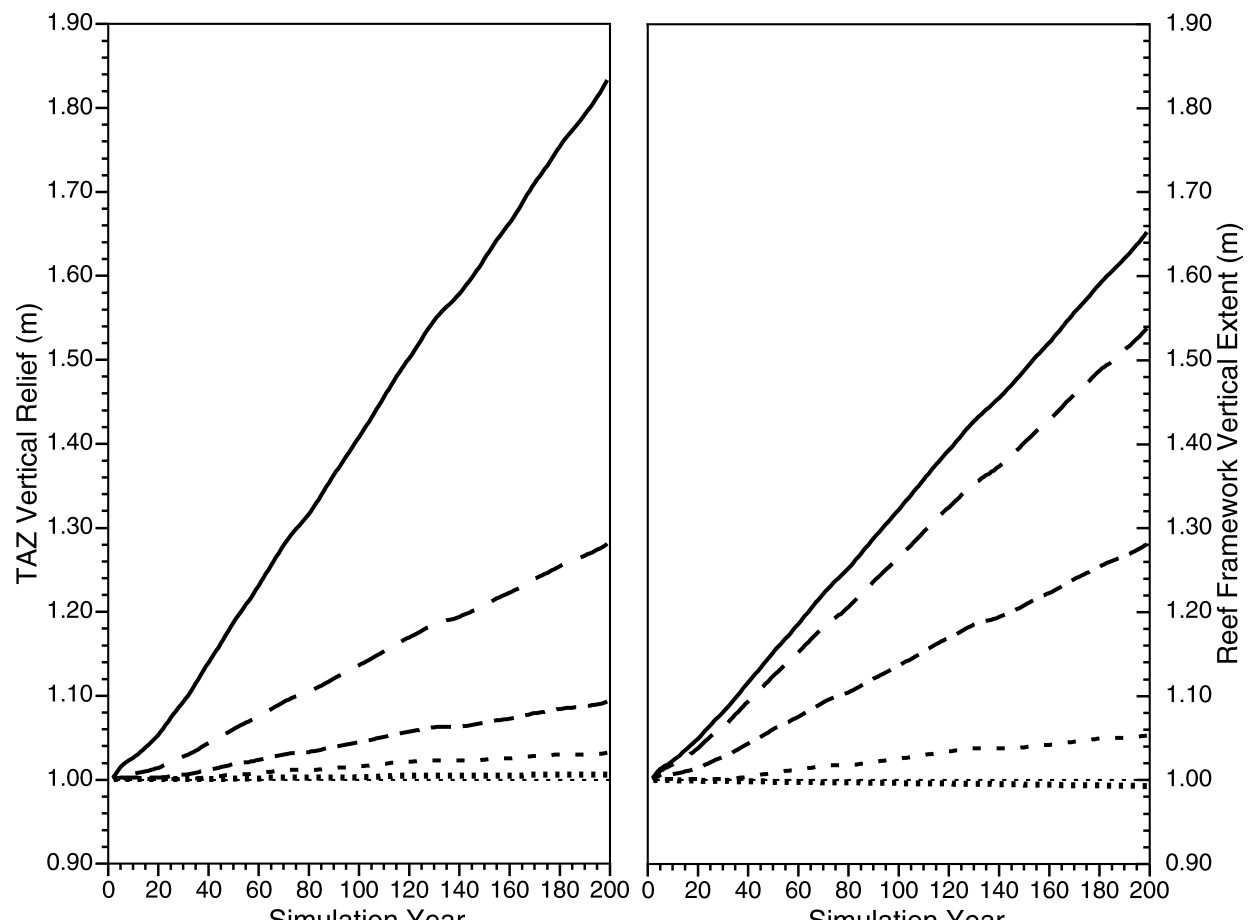

Simulation Year

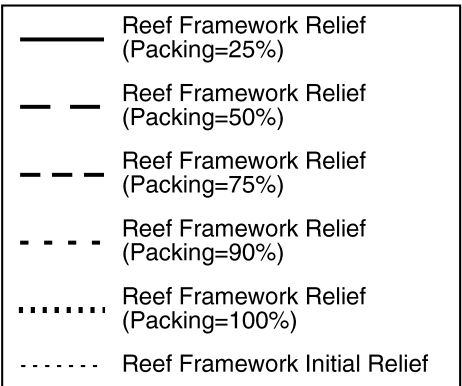

Simulation Year

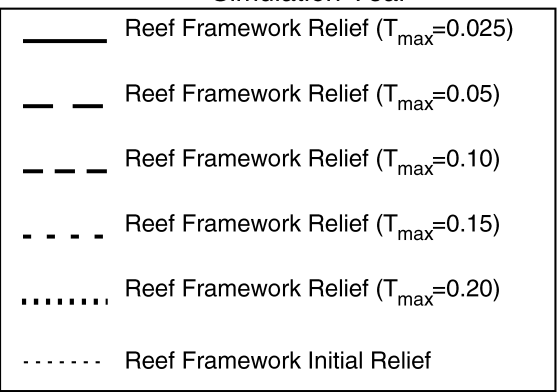

Figure 7. Temporal history of subsurface reef carbonate for a simulated oyster reef derived from the base case for Delaware Bay depicted in Figure 4 (see Table 1 for additional details): left, under five assumed values for MaxPack, the packing coefficient for carbonate at and below the DFB; right, under five assumed values for $T_{\max }$, the maximum vertical extent of the TAZ above the DFB permitted without burial. In the simulations on the right, higher values of $T_{\max }$ coincide with greater sequestration of carbonate in the TAZ and, consequently, with greater surface area available for taphonomic attack. Depicted is the relief of the reef framework relative to the 1-m relief defined at the initiation of the simulation. 


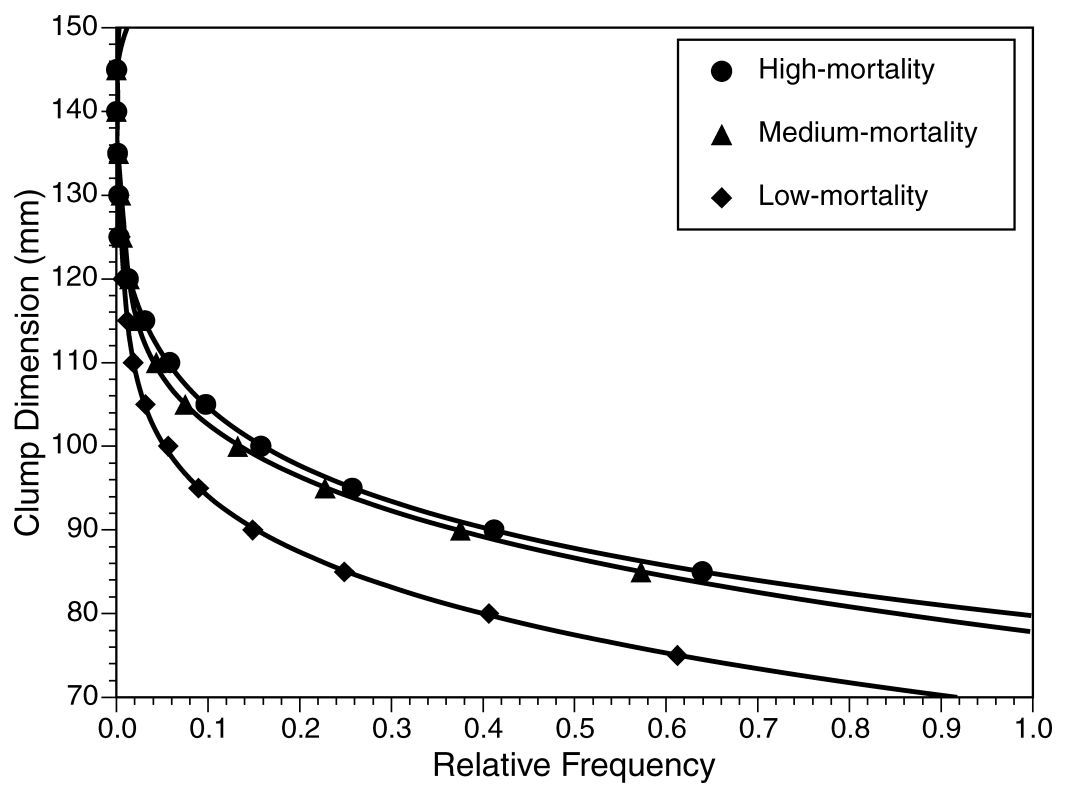

Figure 8. The frequency of collection of clumps of specified size in Delaware Bay survey dredge samples expressed as a relative frequency for three bay regions. Note that the data were obtained by measuring the ten largest clumps in each sample. As a consequence, the relative probability of encountering the largest clumps approximates their relative commonness in situ whereas the probability of encountering smaller clumps (approximately $<80 \mathrm{~mm}$ ) is large, but unknown. The plot shows that clumps $>100 \mathrm{~mm}$ are uncommon regardless of bay region and clumps $>110 \mathrm{~mm}$ are rare. Bay regions are defined in Powell et al. (2008; see their Fig. 1 and Table 1). Fishing effort is high on the high-mortality and medium-mortality beds, but negligible on the low-mortality beds (HSRL, 2010).

One might consider the possibility that half-lives decline with increased subsurface porosity, as is likely the case in bioturbated soft sediments (see for example Meadows and Meadows, 1991; Boudreau, 1986, 1991). Having no information upon which to base such a formulation, we do not include this process in Eq. (10).

v. Distribution of carbonate in the $T A Z-b, T_{\max }, T_{\min }$. The vertical extent of the TAZ is controlled by clump height, parameterized by $T_{\max }$. Data from Delaware Bay suggest that clumps rarely exceed $100 \mathrm{~mm}$ in vertical relief (Fig. 8). A further complication is the likelihood that fishing reduces clump size and frequency. This seems logical although data from Delaware Bay for areas fished and unfished do not reveal remarkably divergent clump heights; indeed they suggest a modestly opposing trend (Fig. 8). We know little about the three-dimensional structure of the living reef on unfished reefs. Information from Powell et al. (1987a) and Wilson et al. (1988) suggest that maximum relief is not substantively higher than observed in Figure 8; however, one certainly suspects that the frequency of larger clumps might be considerably higher in the pristine condition. 
For these and all other simulations, we set the value of $T_{\min }$, the thickness of the shell layer at the base of the TAZ upon and within which the clumps reside, to $2 \mathrm{~cm}$, about the thickness of two oyster shells. The value is unknown [see Aline (2008) for an analogy] and very likely dependent upon porosity and the packing coefficient previously discussed. However, as earlier reviewed, the necessity of a very long half-life for the subsurface shell necessitates that the DFB be very near the objective surface of the reef upon which the clumps rest. Further support comes from the outcome of simulations with $b \ll 1$ as described subsequently. Low values of $b$ can be interpreted as the extension of the TAZ into the reef framework.

The rate of reef accretion is inversely proportional to the vertical extent of the TAZ defined by clump height (Fig. 7). The inverse relationship between the vertical relief of the $\mathrm{TAZ}$ and the rate of reef accretion stems from the fact that an expanded TAZ increases the amount of carbonate exposed to taphonomic processes prior to burial and thus less carbonate survives the vicissitudes of taphonomy until interment. By inference, the production of clumps by oysters limits the vertical accretion rate of reefs. This hypothesis comes with a number of caveats previously described. Moreover, the environment inside the TAZ of a clumpy reef is certainly divergent from the overlying estuarine water [see for example Jumars and Nowell (1984), Peterson et al. (1984), DeAlteris (1989), Coco et al. (2006) for examples of boundary layer processes] and so too may be the rate of taphonomy.

The distribution of carbonate in the TAZ is dependent on the number, height, and volume of clumps. The structure of the surficial reef is very likely highly variable (e.g., Powell et al., 1987a; Rodney and Paynter, 2006; Stiner and Walters, 2008). In the model, the distribution and volume contribution of clumps is primarily controlled by parameter $b$ in Eq. (1). One would assume that pristine reefs are substantively divergent from fished reefs in that the number of clumps and their height might be assumed to be larger (but see Fig. 8). Inasmuch as the structure of the living reef is as yet poorly documented, we investigate a wide range of values for the parameter $b$, yielding distributional patterns that vary from extremely hollow curves to distributions in which carbonate volume exceeds $50 \%$ of total volume over more than half of the TAZ (Fig. 2). These alternatives provide a wide range of simulated outcomes, although all generate nearly stable to increasing reef thicknesses (Fig. 9). Increasing the carbonate volume fraction throughout the TAZ results in reduced carbonate burial and greater carbonate loss. Thus, if more carbonate is stored in the TAZ prior to burial, more is lost through taphonomy prior to burial, and as a consequence, less carbonate is preserved. The value of $b$ likely varies over a wide range of values that generate hollow curves of substantial to extreme hollowness (Fig. 2). Any value that results in carbonate contributing close to half or more of the TAZ volume (e.g., $b \leq 2.0$ in Fig. 2) dramatically limits reef accretion. The assumption of reef accretion over a wide range of values of $b \geq 2$ generating hollow curves (Fig. 9) is consistent with the relative paucity of large clumps (Fig. 8) and suggests that the value of $b$ is unlikely to be among the most significant parameters controlling reef accretion. 

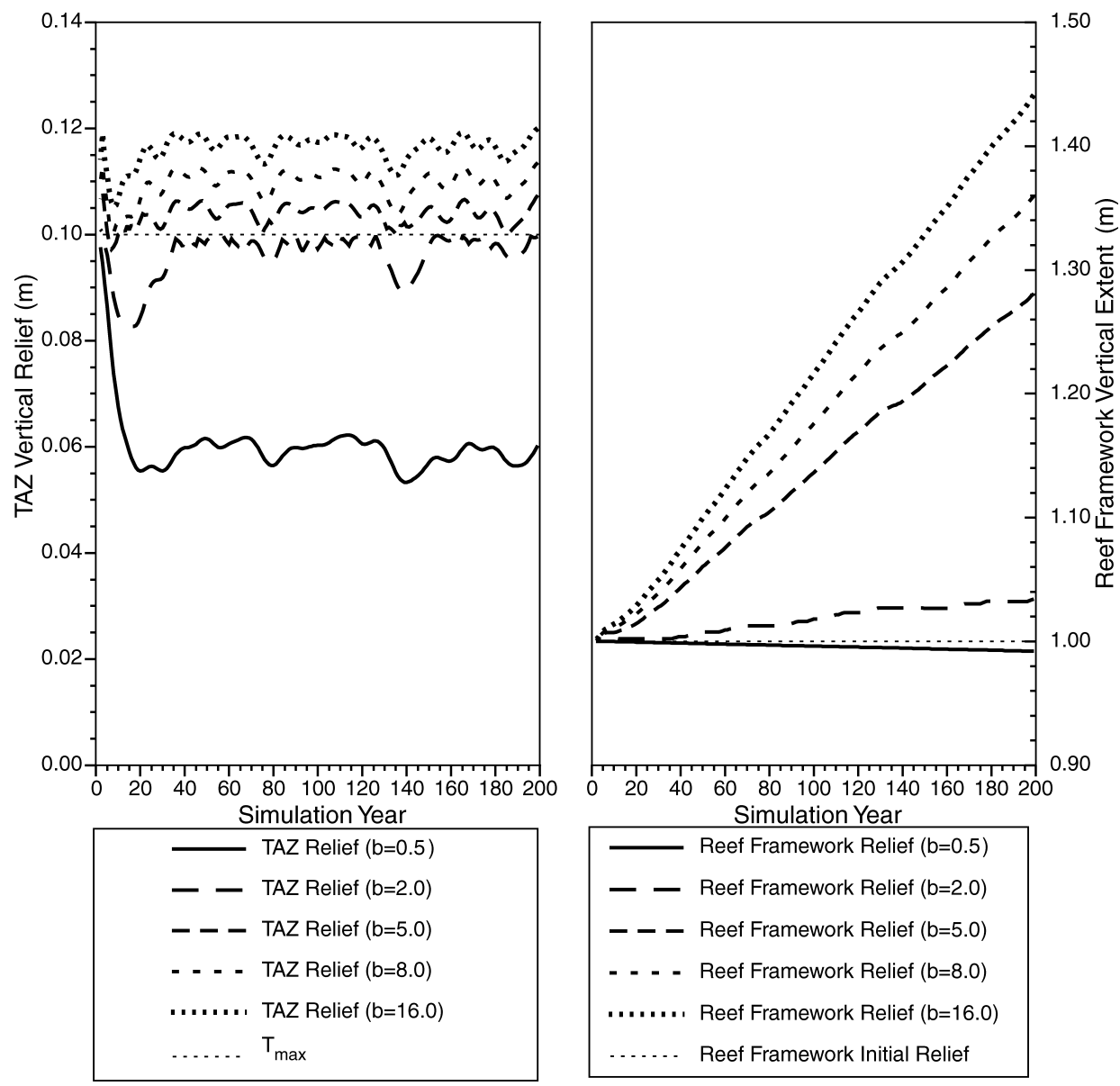

Figure 9. Temporal history of surficial (TAZ) and subsurface reef carbonate for a simulated oyster reef derived from the base case for Delaware Bay depicted in Figure 4 (see Table 1 for additional details) under five assumed values for $b$ (Fig. 2), the variable controlling the distribution of carbonate within the TAZ. Left, the vertical extent of the TAZ over 200 years relative to the threshold eliciting burial of shell $\left(T_{\max }=10 \mathrm{~cm}\right)$. Right, the relief of the reef framework relative to the $1-\mathrm{m}$ relief defined at the initiation of the simulation.

Two additional assumptions of unknown consequence should be considered. First, lower values of $b$ and, hence, larger fractions of the volume of the TAZ occluded by carbonate, might be expected to buffer environmental acid and reduce dissolution (see for example Green et al., 1998, 2004; Tribble, 1993). This possibility is not included in the model. Second, carbonate bound up in the shells of living oysters is not included in the reef carbonate budget and is assumed to suffer minimal loss through taphonomic processes, although boring of live oyster shells is well documented and carbonate loss almost certainly consequential 
in higher salinity regions (e.g., Hopkins, 1956, 1962; Gunter, 1979; Royer et al., 2006). Age-dependent variations in shell weight due to bioerosion are subsumed in Eq. (7) and not further considered. The relative proportion of live-oyster carbonate as a component of the carbonate resource of the TAZ is poorly documented, as is the relative importance of the two for supporting recruitment (e.g., Bahr, 1976; Bahr and Lanier, 1981; Tamburri et al., 2008; Powell et al., 2008a). One might assume that much more carbonate is bound up in living animals in the pristine reef and this in and of itself limits taphonomic loss as the inner shell surface is only exposed at death (Lescinsky, 1993; Cutler, 1995; Kidwell et al., 2001).

vi. Carbonate transport across the DFB $-\alpha_{\max _{F}}, \alpha_{\min _{F}}, \alpha_{\text {slope }_{F}}, \alpha_{\max _{T}}, \alpha_{\text {slope }_{T}}, \beta_{T}$. Remobilization of carbonate into the TAZ from the reef framework during times of reef recession is parameterized by Eq. (12). We assume $\alpha_{\min }$ is near zero; thus buried reef remains inactive unless the base shell layer in the TAZ is reduced to very near the thickness of $T_{\min }$. This seems reasonable as the surficial shell layer on a degrading reef will remain relatively flat and impervious. We arbitrarily set $\alpha_{\max }$ to 0.025 based on the presumed consolidated nature of the reef framework. The parameter $\alpha_{\text {slope }}$ is set to 0.005 so that buried reef is re-exposed, when erosion occurs, only when the surficial carbonate has been reduced to near $T_{\min }$. The corollary assumption is that the vertical complexity of the TAZ is much lower in a receding reef than an accreting reef. We know of no empirical observations to support or refute this presumption. Thus, we assume that buried carbonate is remobilized only when the TAZ becomes less thick than $T_{\min }(2 \mathrm{~cm})$.

As it seems self evident that reef recession will only occur when the basal surficial shell layer becomes very thin, we do not investigate alternative formulations. Although reef loss is well documented [see for example, Mann et al. (2009) and Smith et al. (2001, 2005)], the mechanism of carbonate mobilization is unstudied ${ }^{6}$. Our parameterization of Eq. (12) implies that exhumation of carbonate should be a slow and arduous process limiting exposure of framework carbonate to taphonomic loss. Relaxation of this assumption would result in many cases of reef near-stasis being relegated to the reef-in-recession category in later simulations and sorely minimize the suite of population dynamics that would lead to reef accretion.

Burial of carbonate is described by Eq. (13). The rate of burial should be influenced by the distribution of carbonate within the TAZ. No empirical observations are available to parameterize this process beyond the description of Wreck Shoals by DeAlteris (1988). In the model, we merely require that the burial rate exceed zero only when the TAZ is 'full' of carbonate as dictated by the packing coefficient (Fig. 7) and the parameter $b$ (Fig. 9). However, once these conditions are met, the burial rate may be more or less rapid depending on the increment of carbonate in the TAZ above the maximum permitted without burial. Simulations of different formulations describing the burial rate as a function of carbonate content by varying the values of $\alpha_{\text {slope }}$ and $\beta_{T}$ over a relatively wide range (Fig. 10) suggest

6. Note again, that we distinguish the process of exhumation or erosion from burial through sedimentation, a process that identifies a reef failing to accrete at a sufficiently rapid rate rather than a reef in recession. 


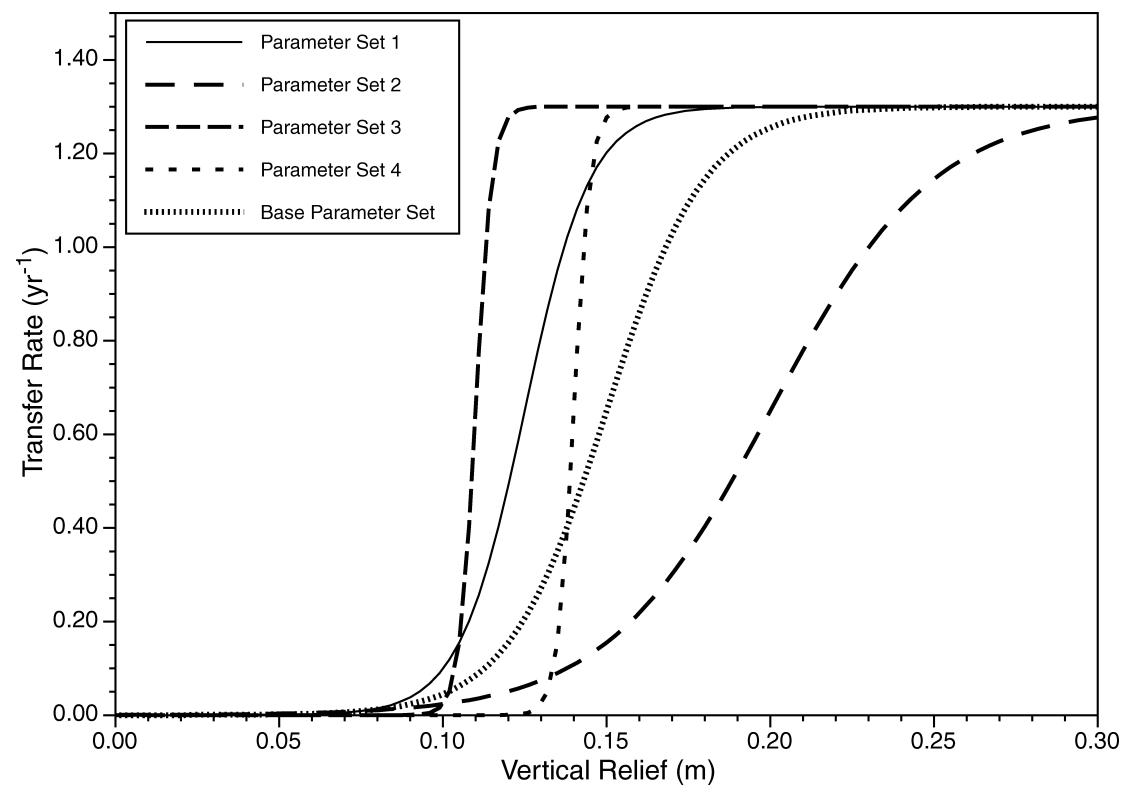

Figure 10. Dependency of the rate of burial of carbonate at the base of the TAZ as a function of vertical thickness of the TAZ for five cases investigated in Figure 11. The parameter sets are: (base) $\alpha_{\text {slope }_{T}}=0.03, \beta_{T}=1.5$; (1) $\alpha_{\text {slope }_{T}}=0.02, \beta_{T}=1.25$; (2) $\alpha_{\text {slope }_{T}}=0.05, \beta_{T}=2.0$; (3) $\alpha_{\text {slope }_{T}}=0.005, \beta_{T}=1.1$; and (4) $\alpha_{\text {slope }_{T}}=0.005, \beta_{T}=1.4$. Note that an increase in vertical relief above $T_{\text {max }}$ implies an accumulation of shell at the base of the TAZ sufficient to result in carbonate burial and preservation.

that rates of reef accretion vary relatively little (Fig. 11), a factor of two in accretion over 200 years in the extreme cases, with the outliers characterized by extensions of the TAZ above $T_{\max }$ to a degree unlikely to occur. Thus, the calculation of the burial rate based on the volume of carbonate in the TAZ is little influenced by the specific formulation used.

vii. Summary. Uncertainty in the model formulation can be related to five parameters descriptive of basic characteristics of the oyster reef and its carbonate content. Two describe the TAZ and the distribution of carbonate within it, $T_{\max }$ and $b$. These depend upon an understanding of variations in clump height and density, an obvious feature of a living reef, but one sparsely documented. Another is the taphonomic rate in the TAZ, $\lambda_{T}$, a parameter known to be variable, for which the source of variability is largely unknown. Two more involve the subsurface framework, namely the volume contribution of carbonate, MaxPack, and the taphonomic loss rate, $\lambda_{F}$, if taphonomic loss occurs at all. As the values for these parameters likely vary considerably between reefs, all following simulations come with a caveat concerning our chosen values: (1) buried carbonate is taphonomically quiescent; (2) carbonate volume contributes about 50\% of total reef volume; (3) clump height is about 

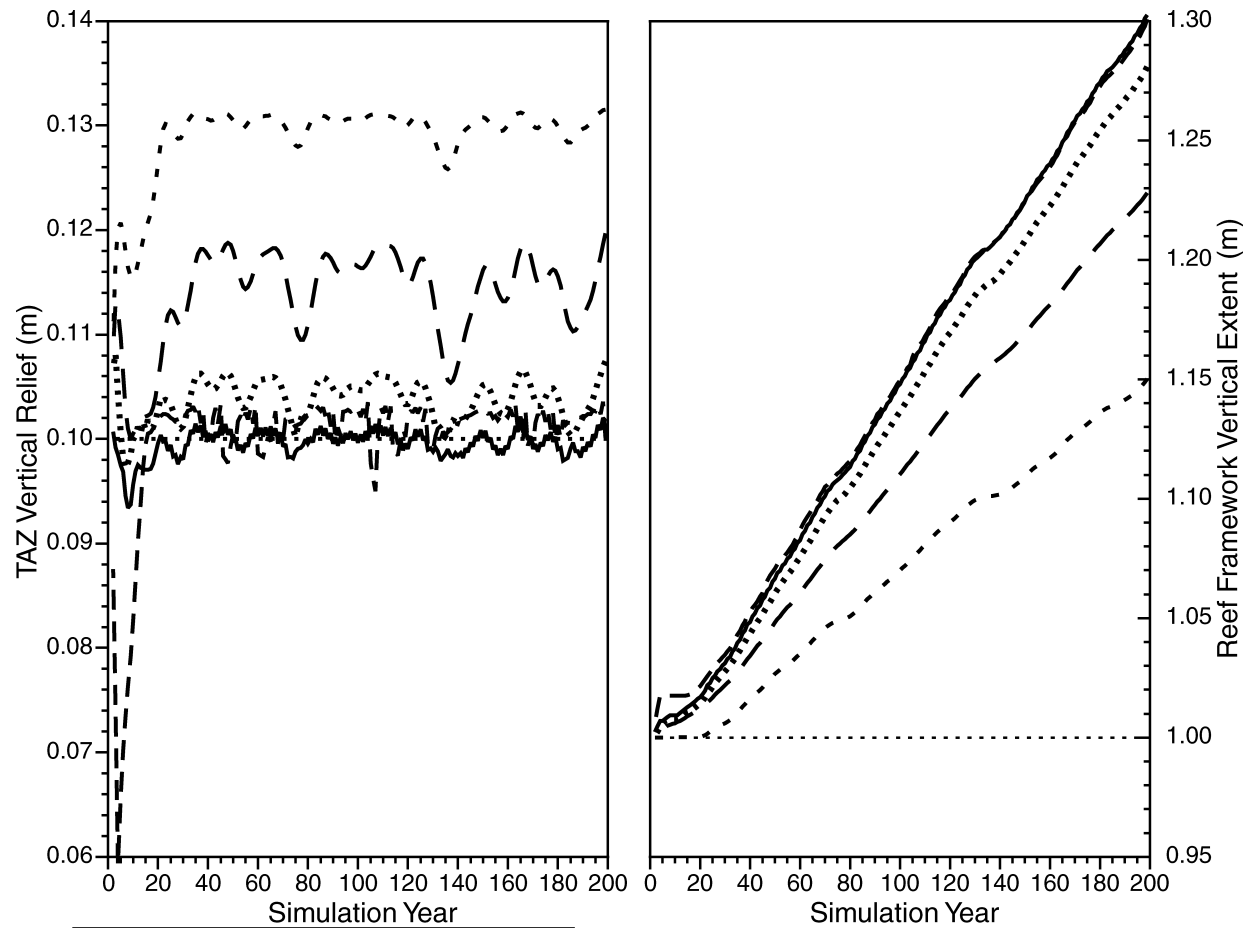

$$
\begin{aligned}
& \text { — TAZ Relief (Parameter Set 1) } \\
& \text { - - TAZ Relief (Parameter Set 2) } \\
& \text { - _ - TAZ Relief (Parameter Set 3) } \\
& \text { - - - - TAZ Relief (Parameter Set 4) } \\
& \text {........ TAZ Relief (Base Parameter Set) } \\
& \text {...... } \mathrm{T}_{\max }
\end{aligned}
$$

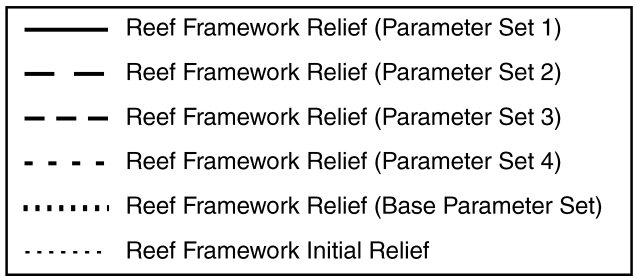

Figure 11. Temporal history of surficial (TAZ) and subsurface reef carbonate for a simulated oyster reef derived from the base case for Delaware Bay depicted in Figure 4 (see Table 1 for additional details) under five assumed combinations of $\alpha_{\text {slope }}$ and $\beta_{T}$, the parameters controlling the relationship between the rate of burial of carbonate and the degree to which carbonate has increased in content in the TAZ beyond that associated with $T_{\max }$. Left, the vertical extent of the TAZ over 200 years relative to the threshold eliciting burial of shell $\left(T_{\max }=10 \mathrm{~cm}\right)$. Right, the relief of the reef framework relative to the 1-m relief defined at the initiation of the simulation. Parameter sets are defined in Figure 10.

$10 \mathrm{~cm}$ and (4) is distributed within the TAZ as a hollow curve $(b=5)$; and (5) a typical taphonomic loss rate for the TAZ is expressed by a 10-year half-life for newly-added shell. All simulations hereafter are proffered under the hypothesis that the Delaware Bay base case thus parameterized (Fig. 4) is a relatively informed approximation of the carbonate budget of the pristine reef. 


\section{d. The influence of population dynamics}

The rate of input of carbonate is, of course, a critical element in determining whether oyster reefs accrete or degrade. Three factors likely dominate the input rate: recruitment that influences abundance, mortality rate that influences abundance, and the size frequency of the animals that die. The recruitment rate of oysters is known to be highly variable (e.g., Loosanoff, 1966; Austin et al., 1996; Southworth and Mann, 2004; Powell et al., 2008a), influenced by regime shifts (Southworth and Mann, 2004; Powell et al., 2009a), and may be related in an as-yet unexplained way to broodstock abundance (Mann and Evans, 1998; Kimmel and Newell, 2007; Powell et al., 2009b).

In a series of simulations, we varied abundance without varying the size frequency of the population. Such an outcome might occur if the broodstock-recruitment relationship changed, but other factors controlling the population dynamics did not. Figure 12 demonstrates the anticipated strong influence of abundance on the dynamics of the reef carbonate budget. Only high abundance generates reef accretion. What is interesting, however, is that lower shell input rates, which result in limited carbonate in the TAZ (low vertical relief values in Fig. 12), result in reef stasis, but only limited degradation. A drop in abundance considerably exceeding a factor of 5 below the carrying capacity of 300 oysters $\mathrm{m}^{-2}$ inferred for Delaware Bay is required to generate distinct loss of reef and even this is minor over the 200 simulated years. Reefs accrete relatively rapidly and recede relatively slowly due to the differential in taphonomic rates between the TAZ and the subsurface tier and the differential in the degree of exposure of carbonate during periods of reef accretion and recession. Note that the model assumes that buried reef is only exposed when the surficial shell is sparse [ $T_{\min }$ in Eqs. (11) and (12)]. Thus, we assume that a thin coating of surficial shell, about 2 shells thick, is sufficient to limit reef recession. Nevertheless, it is a prediction of the model that reefs 'protect themselves' by limiting the rate of transfer of buried carbonate back into the TAZ during times of low shell input.

The rate of carbonate input is a function of abundance and the mortality rate, but also of the size frequency of deaths as oyster shell weight increases as a power function of length [Eq. (7)] (Mann et al., 2009; Powell and Klinck, 2007). The size frequency at death is a complex product of the sources of mortality and the rate of growth, expressed by the vonBertalanffy parameters $k$ and $L_{\infty}$. The growth function exerts a strong influence on the rate of shell addition [Fig. 13 compares three cases taken from Powell et al. (2012), their Figures 8 and 10]. The first case is the base case for Delaware Bay used for previous simulations (e.g., Fig. 4). The second case (labeled 'reduced $L_{\infty}$ case' in Fig. 13) is a Mid-Atlantic case with a lower asymptotic length [e.g., Shell Rock in Delaware Bay (Kraeuter et al. (2007)]. The third case is a case for the Gulf of Mexico with an increased value of $k$, but a similarly low value of $L_{\infty}$ (from Addison, 2006). These cases vary primarily in the size frequency at death and secondarily in the turnover rate of the population. The most rapid rate of reef accretion occurs in the case with the highest $L_{\infty}$ and thus the largest and heaviest shells at death. This outcome is consistent with Mann et al. (2009) who emphasized the importance of large adults in the carbonate budget. The case with least reef accretion is one with both a lower $L_{\infty}$ and a lower $k$. In this simulation, animals grow slowly to a lesser size and so the 

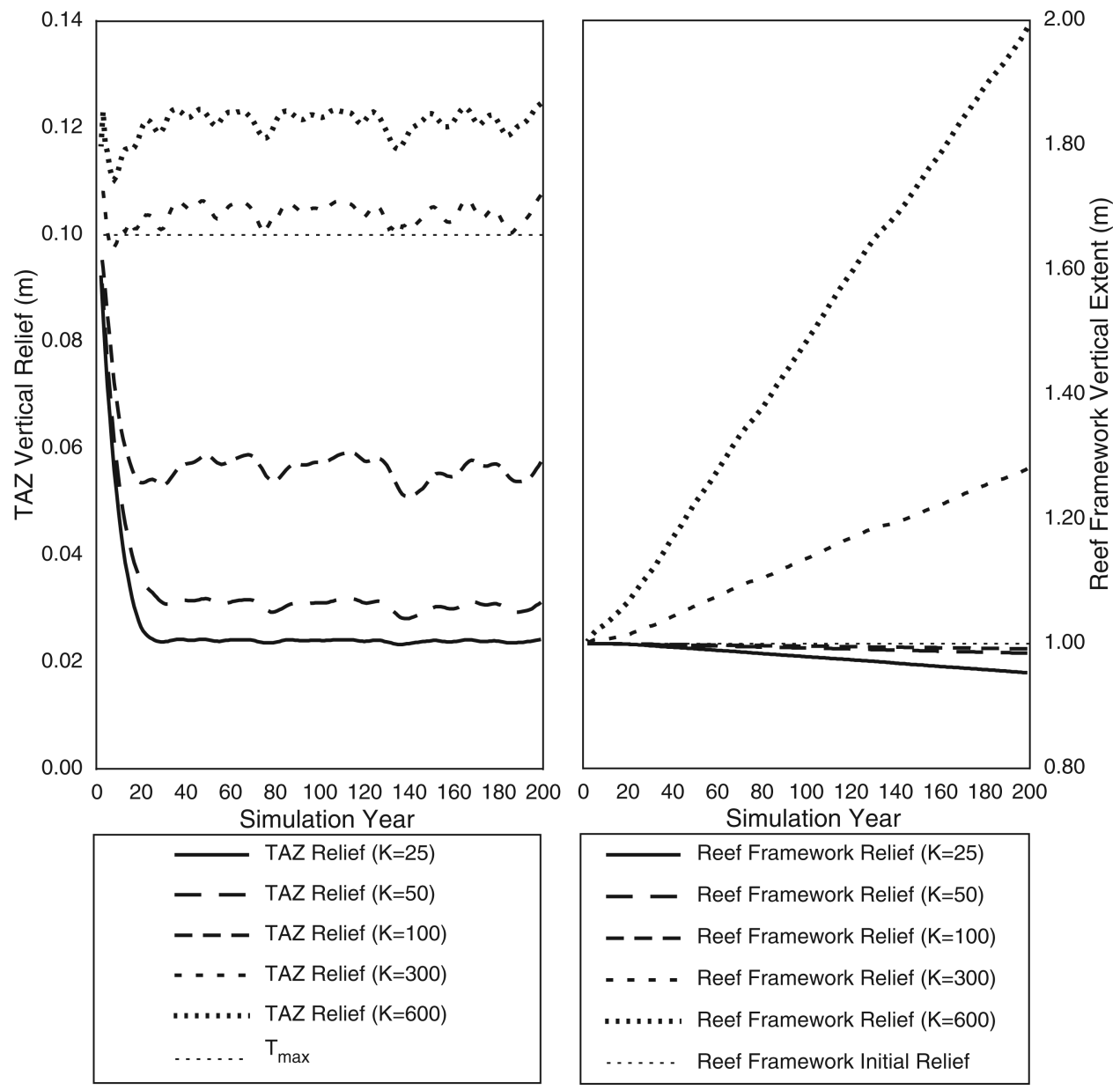

Figure 12. Temporal history of surficial (TAZ) and subsurface reef carbonate for a simulated oyster reef derived from the base case for Delaware Bay depicted in Figure 4 (see Table 1 for additional details) under five assumed values of carrying capacity $K$, expressed in numbers $\mathrm{m}^{-2}$. Left, the vertical extent of the TAZ over 200 years relative to the threshold eliciting burial of shell $\left(T_{\max }=\right.$ $10 \mathrm{~cm}$ ). Right, the relief of the reef framework relative to the $1-\mathrm{m}$ relief defined at the initiation of the simulation.

animals dying average smaller in size. Reef accretion and recession are ineluctably related to the growth dynamics in the population and the age at death of the adult animals.

\section{Dermo disease and fishing: The dynamics of reef budgets in the modern age}

a. Generation time, mortality, and dermo disease

We present three specific cases designed to cover a range of oyster population dynamics. The first is the Delaware Bay case that has served as the base case for this study (Fig. 4). This 


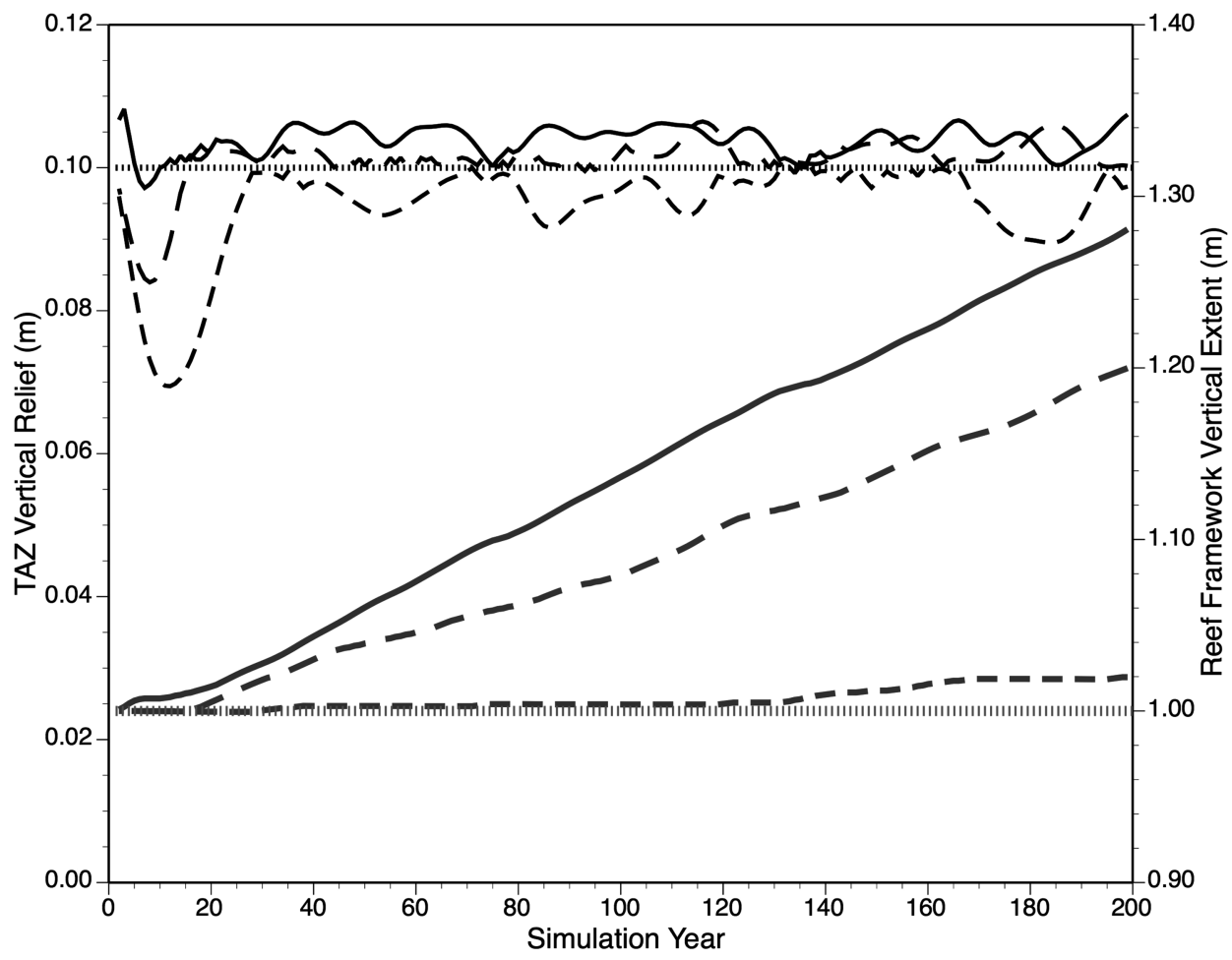

\begin{tabular}{|c|c|c|c|}
\hline - & TAZ Relief (Base Case) & 工 & Reef Framework Relief (Base Case) \\
\hline - - & TAZ Relief (Gulf Case) & - - & Reef Framework Relief (Rapid Growth/Gulf Case) \\
\hline & TAZ Relief (Reduced $\mathrm{L}_{\infty}$ Case) & & Reef Framework Relief (Reduced $\mathrm{L}_{\infty}$ Case) \\
\hline 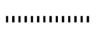 & $\mathrm{T}_{\max }$ & & Reef Framework Initial Relief \\
\hline
\end{tabular}

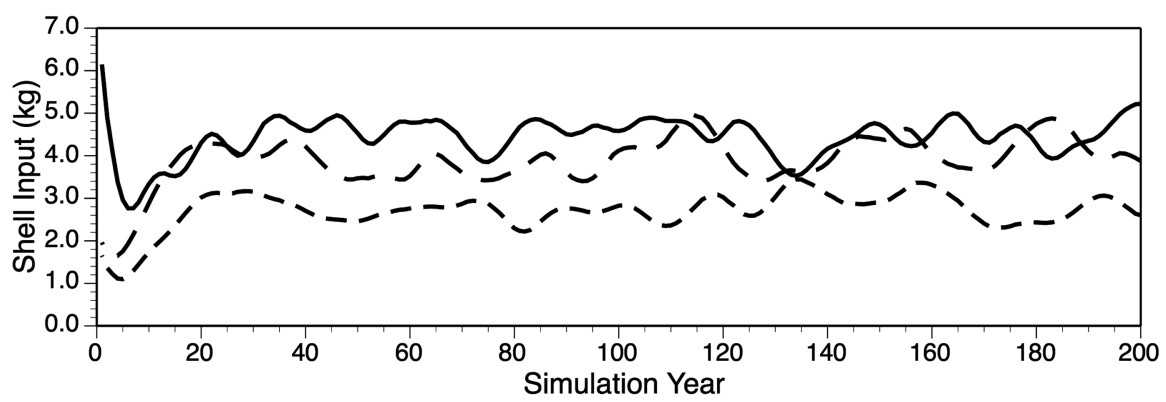

Figure 13. Temporal history of surficial (TAZ) and subsurface reef carbonate for a simulated oyster reef for populations differing in their growth curve, as described by the von-Bertalanffy parameters $L_{\infty}$ and $k$ (see Table 1 for additional details). Above: the vertical extent of the TAZ over 200 years relative to the threshold eliciting burial of shell $\left(T_{\max }=10 \mathrm{~cm}\right)$ and the relief of the reef framework relative to the $1-\mathrm{m}$ relief defined at the initiation of the simulation. Below: The amount of shell added each year per $\mathrm{m}^{2}$ through deaths of living oysters. 
is a case with population abundance sufficient to minimize the vagaries of genetic drift, with a von-Bertalanffy growth curve that permits large old animals to exist in the population, and a 10-13\%-per-year mortality rate. The second is a modified case for Delaware Bay specifically constructed to minimize the population's ability to adapt to dermo disease by developing resistance to the disease because some alleles conferring disease resistance are lost early after the onset of the disease. This is accomplished by assuming a much reduced population abundance, thus facilitating genetic drift. [Note that this is total population abundance, not density or numbers $\mathrm{m}^{-2}$.] The third case is for high-productivity regions of the Gulf of Mexico where two generations can occur yearly (Hopkins, 1954; Mackenzie, 1977; Hayes and Menzel, 1981; Hofmann et al., 1994; Gullian and Aguirre-Macedo, 2009)7

Simulations were run such that a naïve population was followed for 200 years, permitting the trajectory of the reef carbonate budget to be documented in the absence of disease (Fig. 14). At year 201, dermo disease was introduced into the simulated population at two intensities, a high-mortality rate typical of the Gulf of Mexico and the initial epizootics recorded in some reaches of Delaware Bay and a moderate mortality rate typical of other locations within the Mid-Atlantic region of the U.S and the most recent epizootic in Delaware Bay [see Powell et al., 2011c for details; for mortality data, see Mackin and Hopkins (1962); Mackin and Sparks (1962); Powell et al. (2008a, 2009a); Ragone Calvo et al. (2001)]. Over the next 200 years of simulation time, the population was permitted to respond to the disease by developing resistance: the degree to which this occurred is discussed by Powell et al., (2011c, this issue).

Over the first 200 years, each naïve population retained an abundance near a carrying capacity of 300 animals $\mathrm{m}^{-2}$ (Fig. 14). Each population experienced an extraordinary abundance decline in the first few years after disease onset, to values between about $20 \%$ and $50 \%$ of carrying capacity. The degree of decline was larger for the higher mortality rate subset, as anticipated. In most simulations, abundance recovered marginally over the 200 years after disease onset consistent with the slow development of disease resistance that confers a lower mortality rate upon the population, as described by Powell et al. (2011c). But, even after 200 years of exposure, population abundance remained approximately $40 \%-50 \%$ below carrying capacity in the best scenarios.

The reef carbonate budget shows an accreting reef for each naïve population prior to onset of disease. Accretion rate is lower for the Gulf of Mexico consistent with a lower asymptotic size (e.g., Fig. 13) and because a second generation per year is inconsequential for a population at carrying capacity. The surficial shell follows three distinctive trajectories after the onset of disease. For the Gulf case, the vertical relief remains largely unaffected. The rate of reef accretion is transiently slowed, but rapidly returns to a near-carrying-capacity rate, despite lower population abundance. Basically, the higher rate of shell addition as a consequence of the higher mortality rate offsets a potential reduction in shell addition as a consequence of lower abundance in a situation where productivity is high enough 


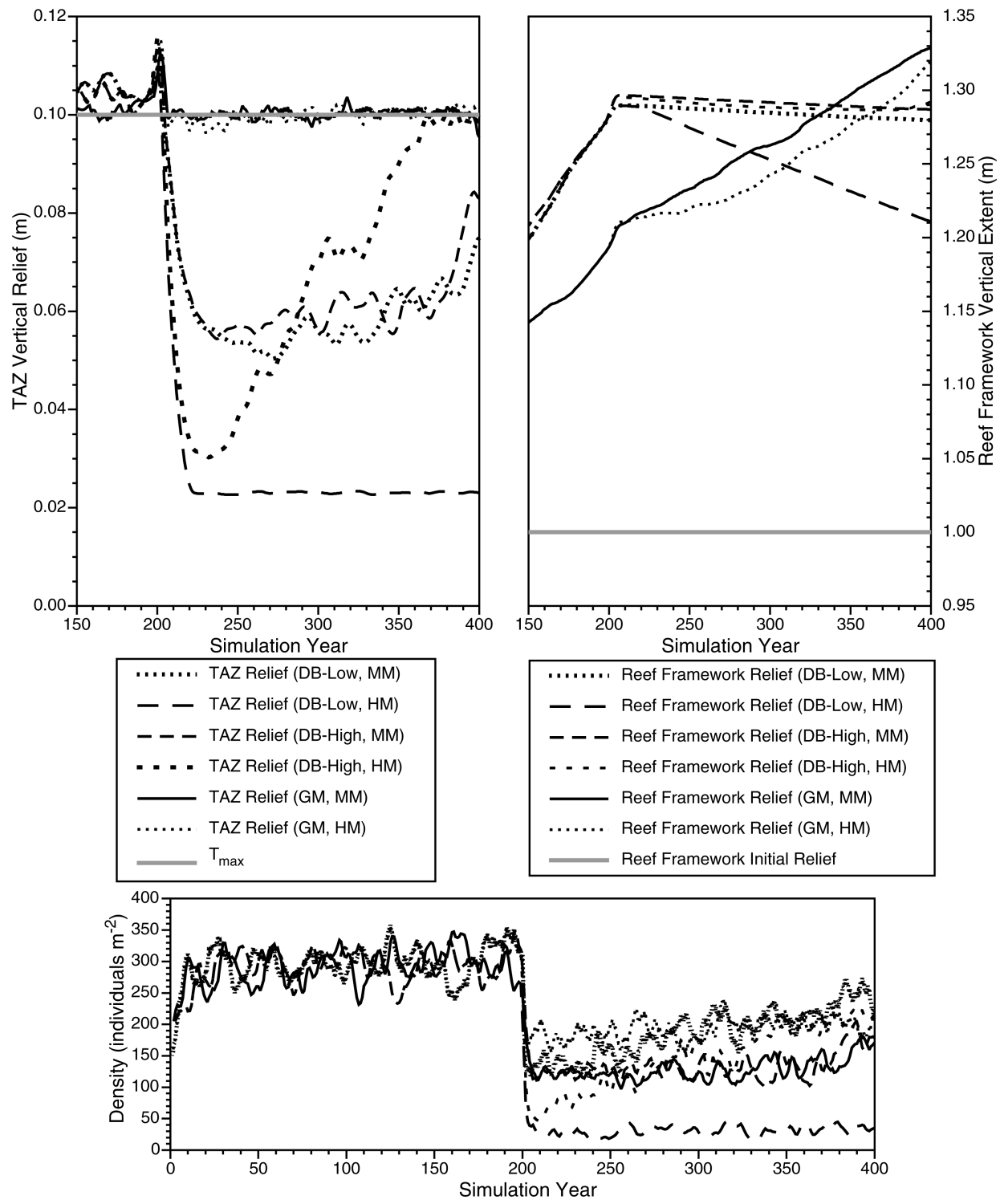

Figure 14. Temporal history of surficial (TAZ) and subsurface reef carbonate for a series of simulated oyster reefs with populations representing widely different population dynamics, including low and high abundance and one and two generations per year (see Table 1 for additional details). Simulations of a naïve population were run for 200 years; the last 50 years are shown. In year 201, dermo disease entered the population and elevated mortality rates to approximating $40 \%$ (HM) and $22 \%(\mathrm{MM})$ per year relative to the approximately $13 \%$ per year prior to disease onset. Legend designations are: DB-Low, a low-abundance Delaware Bay simulation; DB-High, a high-abundance Delaware Bay simulation; GM, a simulation of a Gulf of Mexico population with two generations per year. The three cases are further described in Powell et al. (this issue), their Figures 8 and 12. Above left, the vertical extent of the TAZ over the last 250 of 400 years relative to the threshold eliciting burial of shell $\left(T_{\max }=10 \mathrm{~cm}\right)$. Above right, the relief of the reef framwork relative to the $1-\mathrm{m}$ relief defined at the initiation of the simulation for the last 250 years. Below: Population density in individuals $\mathrm{m}^{-2}$, to be distinguished from total population abundance whch averaged in the first 200 years 1.2 million (DB-High), 400,000 (DB-Low), and 475,000 (GM). 
to maintain a high throughput of animals. For one Delaware Bay case, a low-abundance high-mortality case, carbonate loss exceeds gain, the TAZ carbonate content declines to a low level, and the reef framework begins to degrade. For the remaining Delaware Bay cases, reef stasis occurs. The carbonate production initially declines and a nadir in surficial shell occurs. This depression in cultch volume abates over time as the population develops disease resistance and population productivity increases, but not sufficiently to permit reef accretion to recommence.

The simulations are consistent with the assessment by Mann et al. (2009) who stressed the importance of large old animals in contributing to the total volume of shell input to the reef in the Mid-Atlantic region of the U.S. and with Powell and Klinck (2007) who suggested that the ability for oysters to generate accreting reefs was evolutionarily in equilibrium with a $10 \%$ mortality rate and the age-structure of the population thereby maintained. The simulations identify the Gulf of Mexico as a uniquely different system and one consistent with a documented higher potential for rapid reef accretion (Powell et al., 1995a).

Dermo disease epizootics tend to be cyclic (Powell et al. 1992, 2009a; Soniat et al., 2006, 2009). We borrow two pairs of simulations from Powell et al. (this issue) who examine the influence of cycles on the development of disease resistance. One pair simulated dermo epizootics in a 4-year cycle representative of Gulf of Mexico disease dynamics (Soniat et al., 2009) and typical of the El Niño-Southern Oscillation (Cane, 2005; Tolan, 2007; Thatje et al., 2008); the other pair simulated dermo epizootics in an 8-year cycle, a duration representative of Delaware Bay dynamics (Soniat et al., 2009) and typical of the North Atlantic Oscillation (Bojariu and Gimeno, 2003; Notaro et al., 2006; Soniat et al., 2009). Following the onset of disease in Year 201, surficial shell declines, in some cases remaining depressed for an extended period of time, but then recovers to near carrying-capacity in all but one case as disease resistance develops (Fig. 15). Cyclic disease epizootics imposing a moderate mortality rate result in a lesser decline in surficial shell than cycles imposing a high mortality rate, regardless of cycle period (Fig. 15). However, in all cases, reef accretion ceases. Stasis occurs. This outcome is independent of epizootic cycle period or the degree of mortality imposed.

In most of the cases shown in Figures 14 and 15, onset of dermo disease is accompanied by stasis or recession of the reef, indicative of inadequate rates of shell production. Dermo reduces generation time (Powell et al., 2011c) and, by forcing increased mortality on larger animals, results in a de facto reduction in $L_{\infty}$. As a consequence, abundance declines, reducing total shell input, and the size of animals dying declines, further reducing shell input per each death. Decreased generation time and reduced abundance are ineluctably conflated in $C$. virginica population dynamics because most populations are to some significant degree controlled by one or more oyster diseases that preferentially impact older adults and this perforce reduces generation time while simultaneously decreasing abundance. 

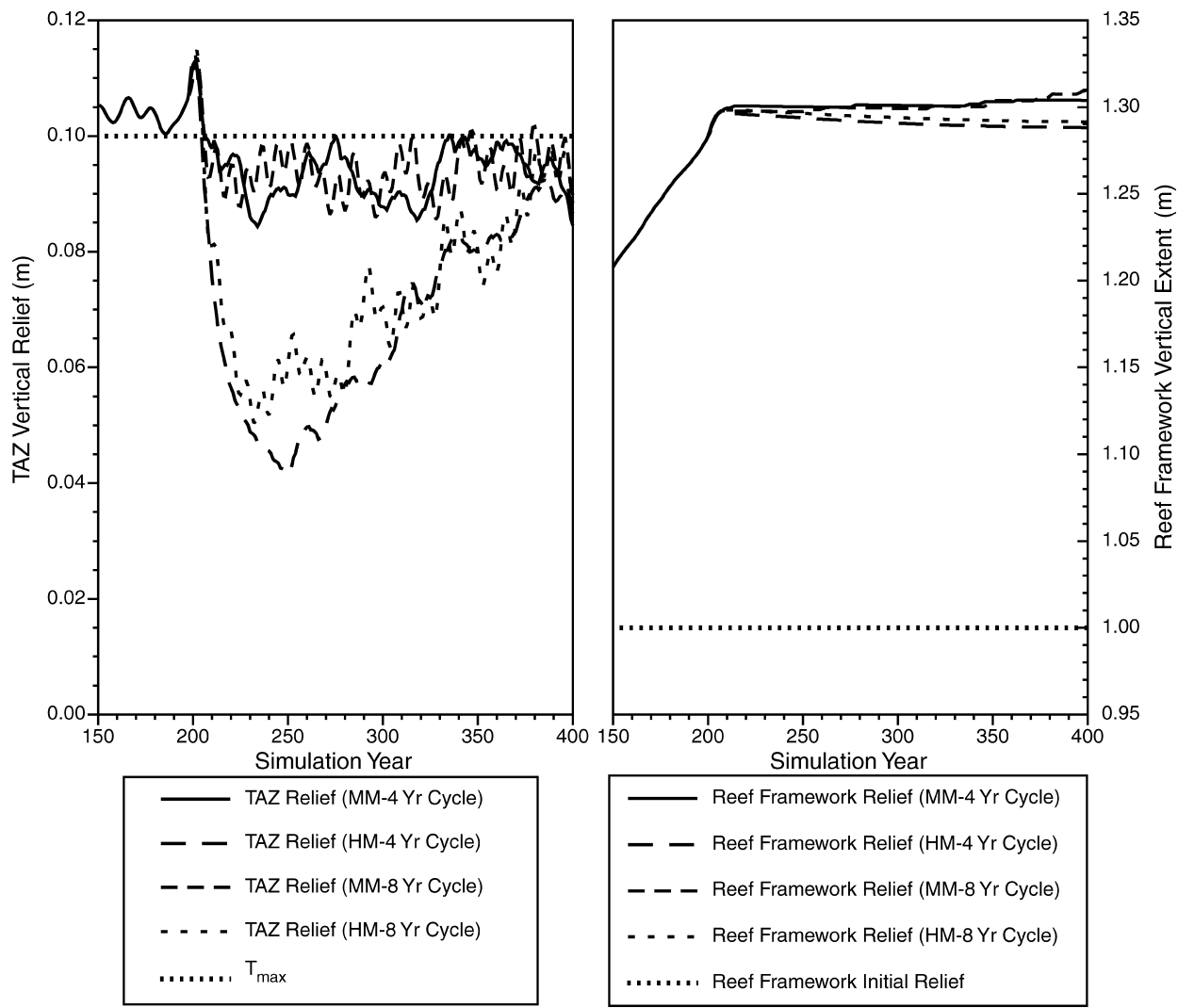

Figure 15. Temporal history of surficial (TAZ) and subsurface reef carbonate for a simulated oyster reef in Delaware Bay (see Table 1 for additional details). Simulations of a naïve population were run for 200 years; the last 50 years are shown. See Figure 4 for a representative full 200-year trajectory. In year 201, dermo disease entered the population and elevated mortality rates to approximating $40 \%$ (HM) and 22\% (MM) per year relative to the approximately $13 \%$ per year prior to disease onset. Dermo mortality rate varied with a 4-year or 8-year periodicity, with cycle zenith equivalent to the previously defined mortality rate and cycle nadir with a mortality rate equivalent to that prior to disease onset. The case for non-cyclic mortality is shown in Figure 14. Left, the vertical extent of the TAZ over the last 250 years of a 400 -year simulation relative to the threshold eliciting burial of shell $\left(T_{\max }=10 \mathrm{~cm}\right)$. Right, the relief of the reef framework relative to the $1-\mathrm{m}$ relief defined at the initiation of the simulation.

\section{b. The influence of fishing}

Dredge fishing modifies the shell bed, reduces abundance, and removes shell from the TAZ. The impact of dredging on the shell bed is mostly speculative. Powell et al. (2001) found that dredging tends to chip shells; this was observed on living oysters that subsequently repaired their shells, but can be assumed also to occur for dead shells. Powell 
and Ashton-Alcox (2004) observed that dredge efficiency declined with repeated dredging, assumably because the degree of consolidation at the base of the TAZ was reduced, thereby increasing porosity. The impact of either on the reef carbonate budget is unknown.

Presumably, however, the vertical relief will be lowered by dredging as clump height is reduced, although data presented in Figure 8 is not strongly supportive of the hypothesis. In all probability, the action of the dredge in breaking down clumps, is likely to make burial of surficial shell more rapid for a given shell mass in the TAZ because more of the carbonate will be distributed across the reef surface rather than conglomerated into clumps. Most likely, increasingly tall clumps will be increasingly rare relative to the unfished reef; that is, the distribution of clump sizes will be skewed more toward single shells. In simulations in Figure 16, we combine these three expectations sequentially, but we do not include the removal of animals by the fishery. Thus, these simulations examine the potential influence of the activity of dredging, not the activity of fishing. The reduction in vertical relief has by far the greatest impact; nevertheless, the summary impact is to increase the rate of reef accretion. The primary reason is that reduced vertical relief results in lesser exposure of carbonate to taphonomic processes in the TAZ and thus a greater proportion of added carbonate is preserved.

Readers may question the decision to impose changes in relief in the surficial tier independent of the degree of fishing pressure. Dredge efficiency is extremely low in dredge fisheries as standardly prosecuted, much lower than when the dredge is used in survey mode (Powell et al., 2002), resulting in a high degree of swept-area coverage at low exploitation rates (Banta et al., 2003). Thus, we assume that the majority of dredging impact on vertical relief is experienced even at the lowest exploitation rates routinely permitted (e.g., Powell et al., 2008a).

The counterintuitive outcome of dredging (Fig. 16) is rectified by taking into account the reduction in abundance and removal of shell mass by fishing (Fig. 17). These simulations were run under the following important constraints. (1) Fishing is imposed as a constant- $F$ (fishing mortality rate) process, not a constant quota process; consistent with sustainable management criteria (Restrepo et al., 1998; Applegate et al., 1998; Powell et al., 2009b). Thus, for example, removal of $10 \%$ of the stock annually results in proportionally more deaths with higher stock sizes. (2) Fishing is assumed to be a knife-edge process with a minimum size of $63 \mathrm{~mm}$ (Powell et al., 2005). (3) Incidental catch of smaller animals is assumed to be minimal (Powell et al., 2005). (4) Discard mortality is assumed to be inconsequential (Powell et al., 2001).

Simulation of three fishing intensities under Delaware Bay population dynamics, with natural mortality set at $13 \%$ per year, consistent with a population existing prior to the onset of disease, shows that a removal of $10 \%$ of the fishable stock yearly permits continued reef accretion, albeit at a slower rate (Fig. 17). A mortality rate of $20 \%$ per year results in near-stasis. A removal of $40 \%$ of the fishable stock yearly results in reef recession (Fig. 17).

All fishing activities result in a contraction of the amount of surficial shell. This is consistent (1) with the assumption that clump height is reduced, (2) with the reduction in 


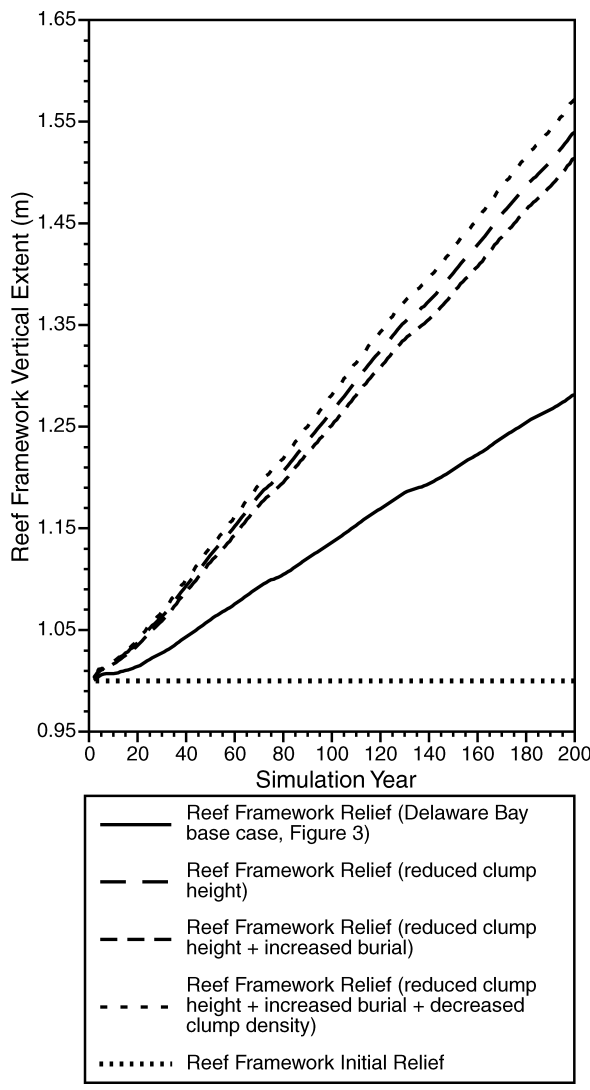

Figure 16. Temporal history of subsurface reef carbonate for a simulated oyster reef in Delaware Bay (see Table 1 for additional details), but modified in keeping with the expectations of the impact of dredge fishing on the TAZ. The 'reduced clump height' cases assumed a reduction in $T_{\max }$ to 0.05 . Increased burial was obtained by setting $\alpha_{\text {slope }}$ to 0.0075 and $\beta_{T}$ to 1.3 in addition to lowering $T_{\max }$. Decreased clump density was obtained by setting $b$ to 8 in addition to modifying $T_{\max }$, $\alpha_{\text {slope }}$, and $\beta_{T}$. Depicted is the relief of the reef framework relative to the 1-m relief defined at the initiation of the simulation.

abundance that results in a decline in the addition of shell to the surficial tier (Fig. 17), and (3) with the removal of otherwise-to-be-contributed shell by the fishery in the form of living animals. The contraction of the surficial shell is consistent with Powell and Klinck (2007) who concluded that any mortality higher than about $10 \%$ per year will result in a reduction of surficial shell.

We also show in Figure 17 the outcome if a reduction in vertical relief is not assumed to accompany fishing. This is an interpretation consistent with data presented in Figure 8, albeit loosely, as the Delaware Bay exploitation rates are lower than those simulated here. The singular difference is the enhanced impact at low fishing intensity. In this case, reef 


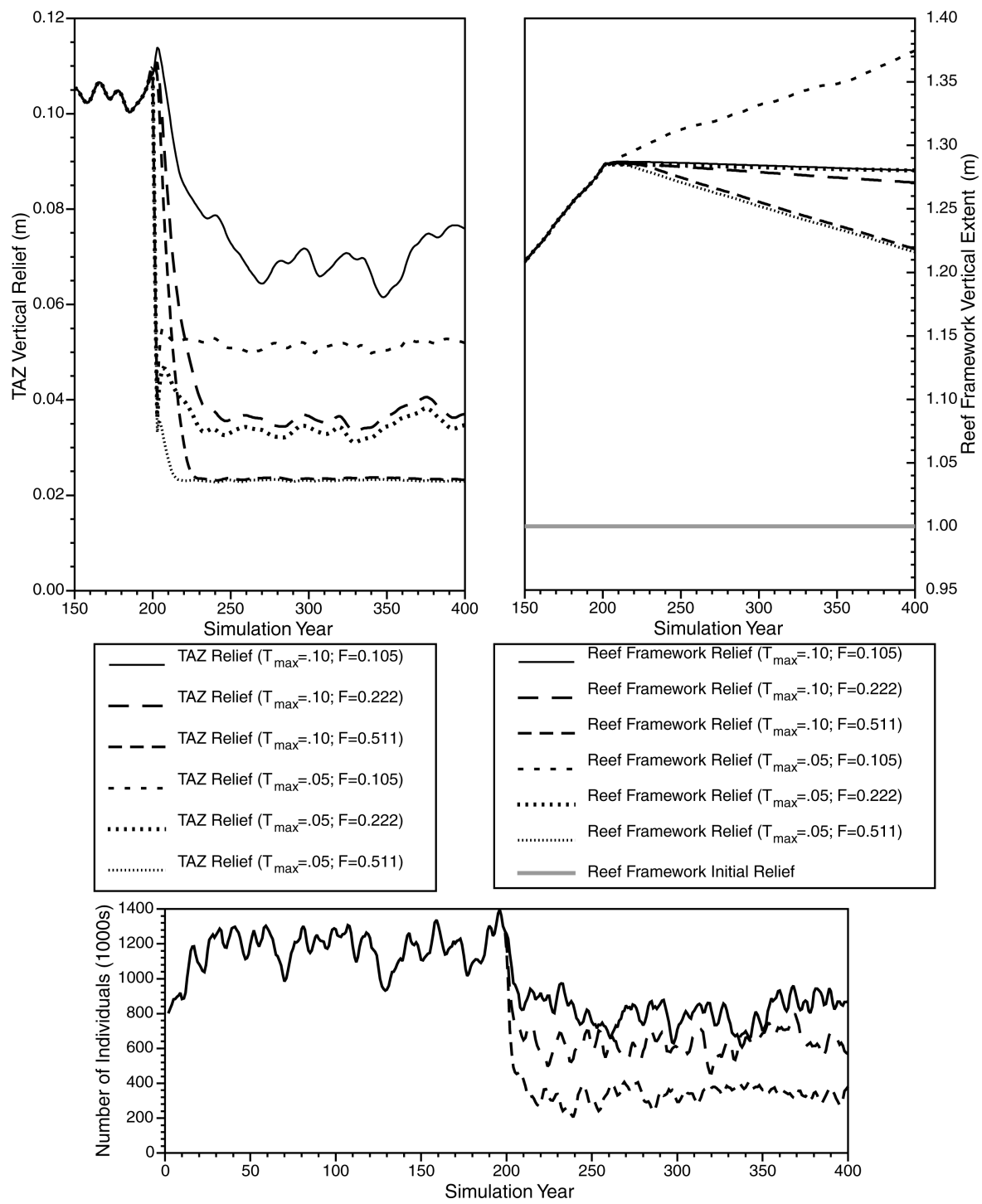

Figure 17. Temporal history of surficial (TAZ) and subsurface reef carbonate for a simulated oyster reef in Delaware Bay with the vertical extent of the TAZ eliciting burial set for the pristine condition and for an anticipated reduction in vertical relief assumed to be the outcome of fishing parameterized by setting $T_{\max }$ to 0.10 and 0.05 , respectively (see Table 1 and Fig. 16 for additional details). In each case, an unfished population was simulated for 200 years: the last 50 years are shown. In year 201, fishing commenced. Fishing was implemented under a constant- $F$ (fishing mortality rate) assumption. Removal rates are equivalent to the removal of $10 \%(F=0.105), 20 \%(F=0.222)$, and $40 \%(F=0.511)$ of the fishable stock yearly. Increased burial was obtained by setting $\alpha_{\text {slope }}$ to 0.0075 and $\beta_{T}$ to 1.3 (Fig. 16). Decreased clump density was obtained by setting $b$ to 8 (Fig. 16). Left, above: the vertical extent of the TAZ over the last 250 years of a 400 year simulation relative to the threshold eliciting burial of shell under pristine conditions $\left(T_{\max }=10 \mathrm{~cm}\right)$. Right above, the relief of the reef framework relative to the 1-m relief defined at the initiation of the simulation. Below: Population abundance; prior to Year 201, population density in each case approximated 300 individuals $\mathrm{m}^{-2}$. 
stasis rather than reef accretion is the result. This occurs because the increased carbonate housed in a vertically-larger TAZ permits increased carbonate loss through taphonomic processes. The proportionately more extreme effect at low fishing pressure occurs because higher fishing rates rob from the TAZ sufficient carbonate that enhanced vertical relief is not retained regardless of model parameterization.

In the case of a high-productivity region in the Gulf of Mexico where two generations per year are feasible, the impact of fishing is relatively similar to Delaware Bay despite the higher potential throughput of animals. Reef accretion can occur under low $F$, but exploitation rates of $20 \%$ per year or more lead to stasis or reef recession. In this case, the higher productivity is balanced by greater removals under the constant- $F$ constraint leading to an increased loss of potential shell input.

\section{c. Simultaneity in dermo and fishing}

In most $C$. virginica populations, dermo mortality and fishing occur simultaneously. Simulations of the Delaware Bay case show that surficial shell was reduced substantively in all cases, including a moderate fishing level of $10 \%$ per year (Fig. 18). At all but the highest fishing rate, some increase in surficial shell content occurred resulting from the increased abundance that developed commensurately with disease resistance over the 200 years. For the 10\%-per-year level of fishing, the volume of cultch in the TAZ tracked by the change in vertical relief of the surficial shell layer in Figure 18 recovered to the volume assumed to be maximal for a fished reef: i.e., $T=T_{\max }=0.05$. However, this recovery did not materialize fully until well into the second century of simulated fishing and disease mortality. In no case did reef accretion occur (Fig. 18). A 10\% fishing rate was characterized by reef stasis. For the two higher fishing rates, reef recession occurred, either modestly or moderately.

Comparison to a high-productivity extremum exemplified by Gulf of Mexico populations producing two generations per year shows a distinctly different outcome from the Delaware Bay case in a number of key particulars (Fig. 18). First, reef accretion continues at low $F$ with dermo disease mortality at moderate (Fig. 18) or high (not shown) rates. No such outcome is obtained in Delaware Bay (Fig. 18). Second, the surficial tier remains shell-rich over a much wider range of $F$ and, in fact, the TAZ is relatively unimpacted from the purportedly pristine condition even at a $20 \%$-per-year exploitation rate. The surficial tier is moderately to significantly shell-poor over the same range of exploitation rates in Delaware Bay, implying a reduced potential for recruitment relative to the Gulf of Mexico case.

\section{Discussion}

\section{a. The reef carbonate budget}

Much attention is given to the maintenance or re-establishment of oyster reefs degraded over time. Generally, fishing has been considered a principal factor in reef degradation. However, recently-increased appreciation of the impermanence of oyster shell has focused attention on all processes that might limit shell addition or encourage shell loss. We present a 

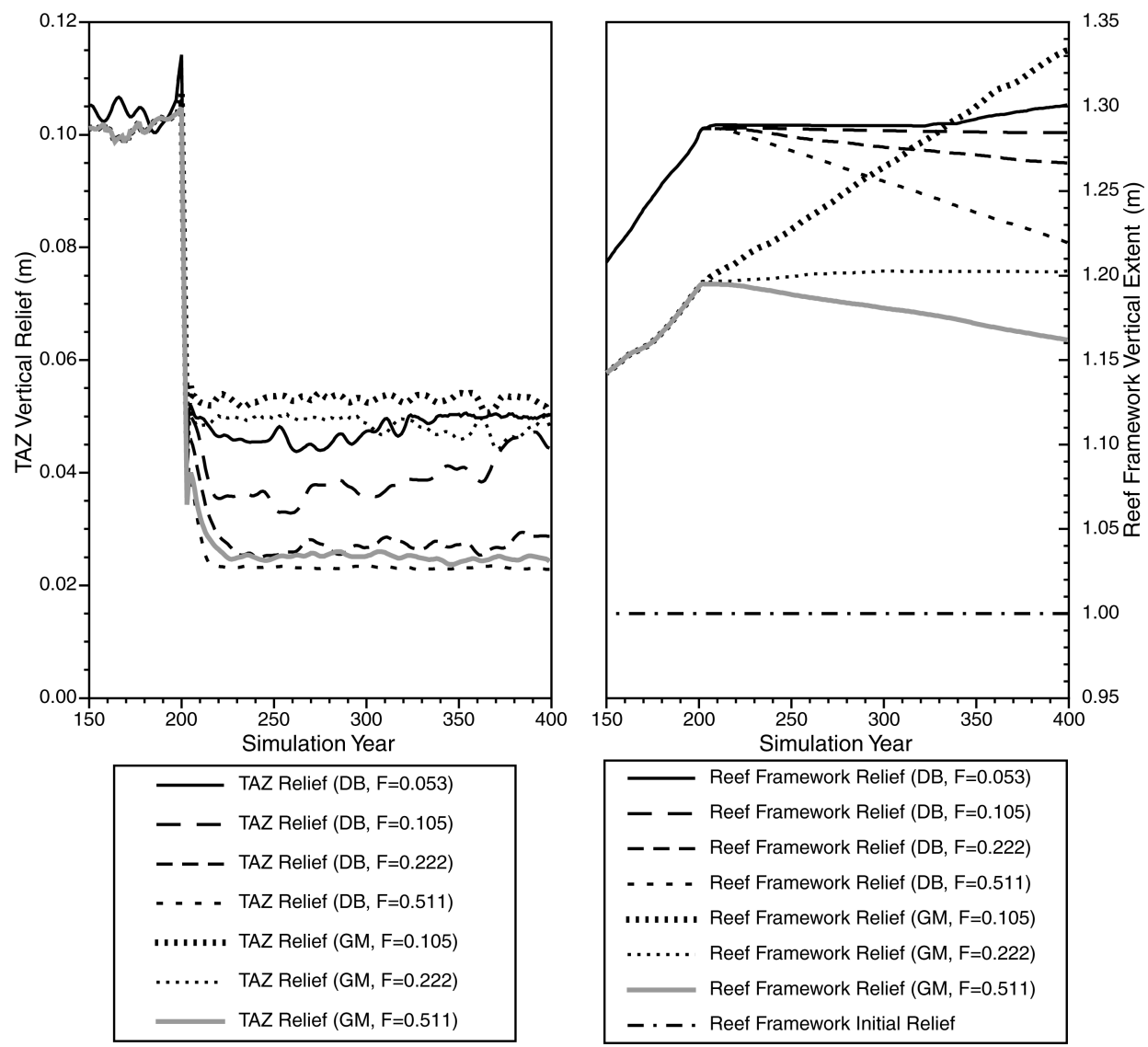

Figure 18. Temporal history of surficial (TAZ) and subsurface reef carbonate for a simulated oyster reef exposed to fishing and dermo disease (see Table 1 for additional details). In year 201, fishing was implemented under a constant- $F$ (fishing mortality rate) assumption. Removal rates are equivalent to the removal of $10 \%(F=0.105), 20 \%(F=0.222)$, and $40 \%(F=0.511)$ of the fishable stock yearly. For Delaware Bay, a removal rate of $5 \%(F=0.053)$ is also shown. Dermo was imposed at a moderate mortality rate, $22 \%$ of the population yearly. DB, a Delaware Bay case; GM, a Gulf of Mexico case from a high-productivity region capable of sustaining two generations per year. Left: the vertical extent of the TAZ over the last 250 years of a 400 -year simulation relative to the threshold eliciting burial of shell for a pristine and a fished reef $\left(T_{\max }=5\right.$ or $\left.10 \mathrm{~cm}\right)$. Right, the relief of the reef framework relative to the 1-m relief defined at the initiation of the simulation. The lower rate of reef accretion prior to year 200 for the Gulf of Mexico originates from the lower value for $L_{\infty}$ used for these simulations (Table 1).

model for the carbonate budget of an oyster reef, building upon earlier treatments by Powell et al. (2006), Powell and Klinck (2007), and Mann et al. (2009). We present this model more in the form of an hypothesis rather than a verifiable representation as the formulation of the model highlights the limited understanding of the mechanisms by which oyster reefs 
accrete and degrade. Basic descriptors such as the vertical distribution of shell within the TAZ, the packing coefficient for the reef, the origin of the wide range of measured halflives for carbonate in the TAZ, and the modulators of burial either are unknown or poorly characterized.

The model and coincident hypothesis provides some interesting speculations, however. First, the anecdotal literature, the treatment of Mann et al. (2009), and the scarcity of empirical observations (e.g., Powell et al., 1995a) all suggest that reef accretion rarely occurs. From DeAlteris (1988), we presume that reef accretion, when it occurs, is both rapid and transient. The model formulated here supports these contentions. For Mid-Atlantic estuarine conditions, reef accretion is only obtained under near-pristine conditions with abundance near carrying capacity. Over geological time, such occurrences must have been recurring, if not common. In the last several centuries, such happenstances have been passingly rare. High-productivity regions of the Gulf of Mexico pose an interesting exception. There, high productivity leading to multiple generations yearly expand the conditions under which reef accretion can occur (e.g., Powell et al., 1995a) and greatly insulate the reef from the depredations of dermo disease and unfettered fishing.

One would think, then, that reefs might rapidly degrade. Such instances are well documented (e.g., Bahr and Lanier, 1981; Haven and Whitcomb, 1983; Mann et al., 2009), but reef stasis is apparently a common state (e.g., DeAlteris, 1988; Powell et al., 1995a). Why? We hypothesize that reefs with limited shell addition respond by reducing the volumetric content of carbonate in the TAZ. As a consequence, carbonate loss is curtailed. The subsurface tier, when exposed, is a mono-layer that minimizes the surface area upon which taphonomy can act. Thus, a dominant outcome in model simulations is the transient expansion and contraction of the shell resource within the TAZ (e.g., Figs. 14, 15, and 17), rarely expanding enough to accrete, yet rarely contracting enough to foster erosion of the reef framework. The model simulations suggest that stasis is a preferred outcome obtained from a wide range of conditions defining the balance between shell addition and loss and that reefs 'protect themselves' by limiting the exposure of framework carbonate to the overlying water while the surficial shell layer deteriorates. Reef recession, by corollary, requires an inordinately unbalanced carbonate budget.

The model suggests that shell in the TAZ, what oyster-reef aficionados consider cultch, is temporally highly variable, waxing and waning as abundance rises and falls. This phenomenon likely explains observed broodstock-recruitment relationships that seemingly are contradictory of the enhancement of recruitment by the planting of shell (e.g., Abbe, 1988; Bowling, 1992; Bushek et al., 2004). Shell planting increases cultch above the level permitted by the equilibrium of natural addition and loss. Thus, the model, indirectly, lends support to the suggestion that the broodstock-recruitment relationship at low abundance records the availability of shell for settlement, not the availability of larvae or the limitation of egg production.

These ruminations strongly argue for expanded focus on the dynamics of the shell resource within the TAZ, as this resource likely fosters a feedback loop with abundance 
through recruitment, serves as the protective layer for the reef during periods of reef stasis, and establishes the threshold conditions for reef accretion and recession. A final ratiocination is the likely requirement that populations be near carrying capacity to promote reef accretion; a condition incompatible with estuarine conditions typical of modern times. Few conditions could be simulated permitting reef accretion at lower population abundance beyond the high-productivity extremum of the Gulf of Mexico.

\section{b. Reef recession, the why of it}

The model suggests that conditions fostering reef recession are not easily obtained. We distinguish this from the case where sedimentation overtops a reef; this is a failure to accrete in competition with regional sedimentation rate, rather than the process of reef recession. A critical requirement for recession to occur is a substantial reduction in oyster abundance. Declining abundance results from increased mortality or declining recruitment. Both are documented (e.g., Ford and Haskin, 1982; Hargis and Haven, 1994; Kimmel and Newell, 2007; Powell et al., 2008a). However, for oysters, two mechanisms of mortality are customarily conjured as explanations, epizootic disease and fishing. Though implicated, neither has been demonstrably identified as the protagonist of reef recession.

Simulations of the impact of dermo disease at frequently-observed mortality levels imposed continuously or cyclically at several periodicities suggest that reef accretion is an infeasible outcome within the Mid-Atlantic for any estuarine reach where dermo is a controlling influence on population dynamics. Simulations also suggest that stasis, rather than recession, is far more likely. Nevertheless, stasis is not a viable outcome in an estuary where sedimentation rates require reef accretion to permit reefs to remain extant. Such conditions are commonplace (e.g., Lenihan, 1999; Smith et al., 2001, 2005; Taylor and Bushek, 2008). Thus, these simulations forecast that dermo will be shown to be a principal constraint on reef survival in the Mid-Atlantic through its negative influence on shell addition rates, contrariwise to the high-productivity regions of the Gulf of Mexico where the impact of disease may impose only a minor constraint on reef accretion (Fig. 14).

The suggestion that increased mortality from disease should reduce shell addition is at first glance counterintuitive. However, dermo exerts its influence in three ways. First, the considerable reduction in oyster abundance limits shell input directly: lower abundance means fewer deaths, even if the mortality rate is higher. Of at least equal importance is the reduction in generation time. Dermo constrains the input of shell from the largest animals by limiting their proportional contribution to the population (Fig. 19). These animals (7+ in Fig. 19) are by far the greatest contributors of shell in the pristine condition. Our model strongly supports the thesis of Mann et al. (2009) that large animals are essential for shell balance. Third, though more uncertain, is the reduction in cultch observed in simulated reefs at stasis. Less surficial shell more or less correlates with the lower abundance (e.g., Fig. 17), and the commensurate likely reduction in available hard substrate for recruitment. Thus, although dermo disease may impose only a minor constraint on fecundity (Choi et al., 1989; 

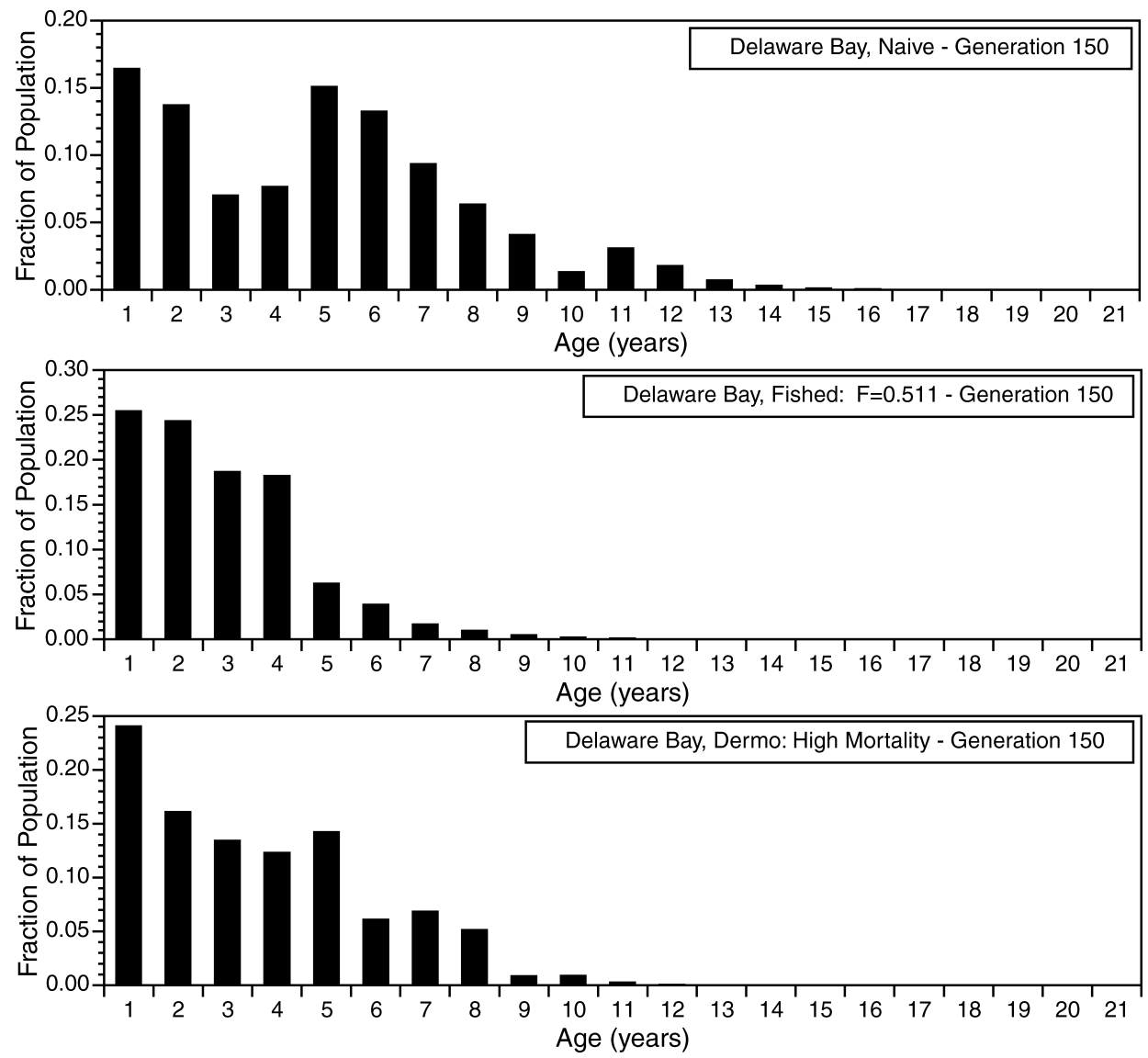

Figure 19. Example size frequencies from a Delaware Bay population (top) unfished and without dermo disease, (middle) exposed to fishing for 150 generations with an exploitation rate of $40 \%$ per year, and (bottom) exposed to dermo disease at a relatively high total mortality rate (HM) of $40 \%$ per year for 150 generations. Note that the y-axis scales differ between plots.

Dittman et al., 2001; Paynter, 1996), it may impose a much larger constraint on recruitment through its influence on the quantity of cultch retained in the TAZ.

Fishing, like dermo disease, reduces abundance and selectively limits shell imput from the largest animals (Fig. 19). Like dermo disease, this reduction in abundance limits outcomes to stasis or recession over a wide range of fishing removal rates. Unlike dermo, careful management may permit a more positive outcome, but only at a low $F$, even though fishing results in the removal of potentially-added shell from the reef. Like dermo, high productivity in the Gulf of Mexico permits greater mortality without jeopardizing habitat integrity. The more positive outcome observed in simulations with fishing only in comparison to simulations with dermo only is solely due to the presumed ability to constrain 
fishing to mortality rates considerably below the mortality rates normally realized in dermo epizootics. Total allowable landing limits have proven to provide this restraint (Powell et al., 2008a).

Most Federal fisherery management plans (FMPs) define biological reference points for fishery management that maintain abundance at $B_{m s y}$ (biomass-maximum-sustainableyield) (e.g., Applegate et al., 1998; Hilborn, 2002; Haltuch et al., 2008; Powell et al., 2009b). Generally, $B_{m s y}$ is defined as half of carrying capacity $K$ based on the standard Schaefer model (Hilborn and Walters, 1992; Maunder, 2003): $B_{m s y}=\frac{1}{2} K$ (but see e.g., Haltuch et al., 2008). For oyster populations prior to the onset of disease, $B_{m s y}$ has been shown to fall near $\frac{K}{2}$ (Powell et al., 2009b). Model simulations suggest that population abundance at $B_{m s y}$ falls below the range permitting reef accretion for Mid-Atlantic estuaries, though not for the Gulf of Mexico. Thus, in the Mid-Atlantic, reef stasis is the likely result of management at $B_{m s y}$. Note in Figure 17 that the potential for reef accretion exists at an abundance value of about $\frac{2}{3} K$, but not at $\frac{K}{2}$, for example. Thus, maximizing production to the fishery and maintaining minimal conditions for reef accretion may be irreconcilable goals aside from some Gulf of Mexico locales.

Powell et al. (2008a) noted that fishing removal rates of 20-25\% per year were incompatible with a sustainable stock. Sustainability was more readily achieved at exploitation rates below $10 \%$ per year. These observations are consistent with the dynamics of reef accretion as modeled here and also with the suggestion that surficial shell is an important determinant of recruitment success. Surficial shell, as modeled here, declines to low levels at exploitation rates much above $10 \%$ per year (Figure 17).

\section{c. Dermo disease and fishing}

Simulations suggest that reef accretion in the Mid-Atlantic cannot occur with a total mortality rate $(Z=M+F)$ exceeding about $20 \%$ per year. No mixture of dermo disease and fishing under Mid-Atlantic conditions permits a total mortality rate this low unless low salinity strongly limits disease mortality. Salinities likely to moderate dermo mortality typically fall below 15\% and potentially nearer 10\% (Andrews, 1988; Powell et al., 1996; Ragone Calvo et al., 2001). Simulations suggest that all but the lowest fishing mortality rates not only doom the reef to stasis, but also severely limit the availability of surficial shell under our hypothesized TAZ dynamics and thus limit the potential for recruitment.

A fishing level of $5 \%$ of the fishable stock yearly is representative of Delaware Bay [the 1997-2009 median is about 3.5\% of the oysters $>2.5^{\prime \prime}$ (HSRL, 2010)]. Powell et al. (2009a, $2009 \mathrm{~b}$ ) suggested that removal rates exceeding 5-10\% of the stock are unsustainable. Even at a low level of fishing of 5\% per year, reef accretion is unlikely (Fig. 18); however, considerable cultch might be retained in the TAZ. That is, the surficial tier would retain a relatively desirable vertical relief and shell content at fishing rates of this order or lower, consistent with Figure 8. The simulations support the exploitation rates implemented in Delaware Bay based on other criteria related to surplus production. 


\section{Conclusions: a vignette on management}

Can the oyster resource in the Mid-Atlantic be managed under present-day disease pressure to achieve a sustainable population and a sustainable habitat? Powell and Klinck (2007), Mann and Powell (2007), Mann et al. (2009), and Harding et al. (2010) suggest that this rarely can be achieved. Simulations of this reef carbonate-budget model identify few successful options. Natural mortality rates in Mid-Atlantic estuaries are too high for reef accretion to occur over much of the estuarine salinity gradient even in the absence of fishing. One consequence of a tacit appreciation of this dilemma is the attention given to reef restoration for habitat (e.g., Breitburg et al., 2000; Meyer and Townsend, 2000; Brumbaugh et al., 2006; Gregalis et al., 2008; Olsen et al., 2006; Cohen and Zabin, 2009) and shell planting for recruitment enhancement (e.g., Gunter, 1972, 1979; Southworth and Mann, 1998). However, these activities require a vast investment of money, time, and effort for optimal results, but barely more than a negligible body of data is available upon which to design an optimal program or even to define the characteristics of a reasonable goal. Critical controlling parameters of the carbonate budget remain poorly characterized.

Nevertheless, an oft-stated aspiration is the restoration of an earlier reef footprint, one present prior to the onset of disease and the overharvesting that characterized even the early years of the better-managed present-day fisheries. Such a goal appears unachievable: reef stasis appears to be the only attainable goal. However, an appropriately limited fishery would permit a quantity of surficial shell conducive to adequate recruitment and sufficient to limit loss of reef framework, under conditions that restrict the impact of sedimentation on habitat integrity. An expanded subset of options may be achieved in many areas through careful management plus the addition of shell to maintain an adequate surficial shell resource in the TAZ.

The model supports earlier suggestions by and inferences from Powell and Klinck (2007), Mann and Powell (2007), and Mann et al. (2009) that successful management of the oyster reef habitat in Mid-Atlantic estuaries is incompatible with fishery exploitation rates exceeding about $5 \%$ of the fishable stock. Higher removal rates at the very least result in a severe loss of surficial shell and a contraction of the TAZ with accompanying loss of recruitment potential. Such low fishing levels are consistent with estimates of removal rates obtained using population dynamics criteria and estimates inferred from long-term time series. The oyster in the Mid-Atlantic region is not resilient to high exploitation rates over significant periods of time, and neither is the habitat upon which it depends. What resiliency existed has been absorbed by the depredations of dermo (and MSX) disease, leaving managers with an extraordinarily limited repertoire and habitat restorers with an intractable obstacle to success.

The impact of changing ocean $\mathrm{pH}$ on calcification and carbonate preservation is becoming well documented (Wootten et al., 2008; Cohen and Holcomb, 2009; Fabry et al., 2009; Miller et al., 2009). Calcification rates of many carbonate producers are expected to decline (e.g., Kleypas and Yates, 2009; De'ath et al., 2009) with consequent impacts on ecosystem services and shellfisheries (Cooley et al., 2009). The commensurate adjustment in 
taphonomic decay rates has been little considered by comparison (e.g., Waldbusser et al., 2011), although both bioerosion and dissolution can be expected to be affected. Because taphonomic decay tends to be a persistent process independent of the temporal vagaries of biological production of carbonate, any increase in taphonomic rates will exact a disproportionate impact on the carbonate budget and further restrict the conditions under which oyster reef development and persistence can occur.

Acknowledgments. Funding was provided by the NSF Biocomplexity in the Environment program grant \#OCE-0412696, the NSF Ecology of Infectious Diseases program grant \#OCE-0622672, and the National Sea Grant Oyster Disease Research Program grant \#NA07OAR4170047. We appreciate this support.

\section{REFERENCES}

Abbe, G. R. 1988. Population structure of the American oyster, Crassostrea virginica, on an oyster bar in central Chesapeake Bay: changes associated with shell planting and increased recruitment. J. Shellfish Res., 7, 33-40.

Abell, M., J. Braselton and L. Braselton. 2005. A host-microparasite model with a resistant host. Ecol. Complexity, 2, 300-311.

Addison, C. 2006. Oyster recruitment and early growth patterns in the Barataria Estuary. Masters Thesis, Nicholls State University, Thibodaux, Louisiana. 119 pp.

Aline, T. 2008. Dissolution of dead corals by euendolithic microorganisms across the northern Great Barrier Reef (Australia). Microb. Ecol., 55, 569-580.

Allen, J. R. L. 1974. Packing and resistance to compaction of shells. Sedimentology, 21, 71-86.

Aller, J. Y. 1995. Molluscan death assemblages on the Amazon shelf: implication for physical and biological controls on benthic populations. Palaeogeogr. Palaeoclimatol. Palaeoecol., 118, 181212.

Andrews, J. D. 1979. Oyster diseases in Chesapeake Bay. Mar. Fish. Rev., 41(1-2), 45-53.

J. D. 1988. Epizootiology of the disease caused by the oyster pathogen Perkinsus marinus and its effects on the oyster industry. Am. Fish. Soc. Spec. Publ., 18, 47-63.

Applegate, A., S. Cadrin, J. Hoenig, C. Moore, S. Murawski and E. Pikitch. 1998. Evaluation of existing overfishing definitions and recommendations for new overfishing definitions to comply with the sustainable fisheries act. Overfishing Definition Review Panel Final Rpt. NOAA, NMFS, $179 \mathrm{pp}$.

Austin, H. M., D. Evans and D. S. Haven. 1996. A retrospective time series analysis of oyster, Crassostrea virginica, recruitment (1946-1993). J. Shellfish Res., 15, 565-582.

Bahr, L. M. 1976. Energetic aspects of the intertidal oyster reef community at Sapelo Island, Georgia (USA). Ecology, 57, 121-131.

Bahr, L. M. and W. P. Lanier. 1981. The ecology of intertidal oyster reefs of the south Atlantic coast: a community profile. U.S. Fish Wildl. Serv., FWS/OBS-81/15, 105 pp.

Banta, S. E., E. N. Powell and K. A. Ashton-Alcox. 2003. Evaluation of dredging effort by the Delaware Bay oyster fishery in New Jersey waters. N. Am. J. Fish. Manag., 23, 732-741.

Barber, B. J., S. E. Ford and R. N. Wargo. 1991. Genetic variation in the timing of gonadal maturation and spawning of the Eastern oyster, Crassostrea virginica (Gmelin). Biol. Bull. (Woods Hole), 181, 216-224.

Beck, M. W., R. D. Brumbaugh, L. Airoldi, A. Carranza, L. D. Coen, C. Crawford, O. Defeo, G. J. Edgar, B. Hancock, M. Kay, H. Lenihan, M. W. Luckenbach, C. L. Toropova \& G. Zhang. 
2009. Shellfish reefs at risk. A global analysis of problems and solutions. The Nature Conservancy, Arlington, Virginia, $52 \mathrm{pp}$.

Best, M. M. R. 2008. Contrast in preservation of bivalve death assemblages in siliciclastic and carbonate tropical shelf settings. Palaios, 23, 796-809.

Best, M. M. R. and S. M. Kidwell. 2000. Bivalve taphonomy in tropical mixed siliciclastic-carbonate settings. I. Environmental variation in shell condition. Paleobiology, 26, 80-102.

Best, M. M. R., T. C. W. Ku, S. M. Kidwell and L. M. Walter. 2007. Carbonate preservation in shallow water environments: unexpected role of tropical siliciclastics. J. Geol., 115, 437-456.

Bojariu, R. and L. Gimeno. 2003. Predictability and numerical modelling of the North Atlantic Oscillation. Earth-Sci. Rev., 63, 145-168.

Boudreau, B. P. 1991. Modelling the sulfide-oxygen reaction and associated $\mathrm{pH}$ gradients in porewaters. Geochim. Cosmochim. Acta, 55, 145-159.

- 1986. Mathematics of tracer mixing in sediments: II. Nonlocal mixing and biological conveyorbelt phenomena. Am. J. Sci., 286, 199-238.

Bowling, B. G. 1992. Rehabilitation of public oyster reefs damaged by a natural disaster in Galveston Bay. Tex. Parks Wildl. Dept. Manage. Data Ser., No. 8, 46 pp.

Breitburg, D. L., L. D. Coen, M. W. Luckenbach, R. Mann, M. Posey and J. A. Wesson. 2000. Oyster reef restoration: convergence of harvest and conservation strategies. J. Shellfish Res., 19, 371377.

Breitburg, D. L. and R. S. Fulford. 2006. Oyster-sea nettle interdependence and altered control within the Chesapeake Bay ecosystem. Estuaries Coasts, 29, 776-784.

Brumbaugh, R. D., M. W. Beck, L. D. Coen, L. Craig and P. Hicks. 2006. A practitioners guide to the design \& monitoring of shellfish restoration projects. An ecosystem services approach. The Nature Conservancy, Arlington, Virginia, $30 \mathrm{pp}$.

Burdige, D. J., X. P. Hu, R. C. Zimmerman. 2010. The widespread occurrence of coupled carbonate dissolution/precipitation in surface sediments on the Bahamas Bank. Am. J. Sci., 310, 492-521.

Burreson, E. M. and L. M. Ragone Calvo. 1996. Epizootiology of Perkinsus marinus disease of oysters in Chesapeake Bay, with emphasis on data since 1985. J. Shellfish Res., 15, 17-34.

Bushek, D., D. Richardson, M. Y. Bobo and L. D. Coen. 2004. Quarantine of oyster shell cultch reduces the abundance of Perkinsus marinus. J. Shellfish Res., 23, 369-373.

Callender, W. R., E. N. Powell and G. M. Staff. 1994. Taphonomic rates of molluscan shells placed in autochthonous assemblages on the Louisiana continental slope. Palaios, 9, 60-73.

Cane, M. A. 2005. The evolution of El Niño, past and future. Earth Planet. Sci. Lett., 230, 227-240.

Carriker, M. R., R. E. Palmer and R. S. Prezant. 1980. Functional ultramorphology of the dissoconch valves of the oyster Crassostrea virginica. Proc. Natl. Shellfish. Assoc., 70, 139-183.

Carver, C. E., I. Thériault and A. L. Malley. 2010. Infection of cultured eastern oysters Crassostrea virginica by the boring sponge Cliona celeata, with emphasis on sponge life history and mitigation strategies. J. Shellfish Res., 29, 905-915.

Cerco, C. F. and M. R. Noel. 2007. Can oyster restoration reverse cultural eutrophication in Chesapeake Bay? Estuaries Coasts, 30, 331-343.

Choi, K-S., E. A. Wilson, D. H. Lewis, E. N. Powell and S. M. Ray. 1989. The energetic cost of Perkinsus marinus parasitism in oysters: quantification of the thioglycollate method. J. Shellfish Res., 8, 125-131.

Coco, G., S. F. Thrush, M. O. Green and J. E. Hewitt. 2006. Feedbacks between bivalve density, flow, and suspended sediment concentration on patch stable states. Ecology, 87, 2862-2870.

Coen, L. D., R. D. Brumbaugh, D. Bushek, R. Grizzle, M. W. Luckenbach, M. H. Posey, S. P. Powers and S. G. Tolley. 2007. Ecosystem services related to oyster restoration. Mar. Ecol. Prog. Ser., 341, 303-307. 
Cohen, A. L. and M. Holcomb. 2009. Why corals care about ocean acidification: uncovering the mechanism. Oceanography, 22, 118-127.

Cohen, A. N. and C. J. Zabin. 2009. Oyster shells as vectors for exotic organisms. J. Shellfish Res., 28, 163-167.

Cooley, S. R., H. L. Kite-Powell and S. C. Doney. 2009. Ocean acidification's potential to alter global marine ecosystem services. Oceanography, 22, 172-181.

Cotter, S. C., L. E. B. Kruuk and K. Wilson. 2004. Costs of resistance: genetic correlations and potential trade-offs in an insect immune system. J. Evol. Biol., 17, 421-429.

Cummins, H., E. N. Powell, R. J. Stanton, Jr. and G. Staff. 1986. The size-frequency distribution in palaeoecology: the effects of taphonomic processes during formation of death assemblages in Texas bays. Palaeontology (Lond.)., 29, 495-518.

Cutler, A. H. 1995. Taphonomic implications of shell surface textures in Bahia la Choya, northern Gulf of California. Palaeogeogr. Palaeoclimatol. Palaeoecol., 114, 219-240.

Davies, D. J., E. N. Powell and R. J. Stanton Jr. 1989. Relative rates of shell dissolution and net sediment accumulation - a commentary: can shell beds form by the gradual accumulation of biogenic debris on the sea floor? Lethaia, 22, 207-212.

DeAlteris, J. T. 1988. The geomorphic development of Wreck Shoal, a subtidal oyster reef of the James River, Virginia. Estuaries, 11, 240-249.

- 1989. The rate of bottom current and estuarine geomorphology on the sedimentation processes and productivity of Wreck Shoal, an oyster reef of the James River, Virginia, in Estuarine circulation, B. J. Neilson, A. Kuo and J. Brubaker, eds., Clifton, New Jersey, The Humana Press Inc., 279_ 307.

De'ath, G., J. M. Lough and K. E. Fabricius. 2009. Declining coral calcification on the Great Barrier Reef. Science (Wash. D.C.), 323, 116-119.

Dittman, D. E., S. E. Ford and D. K. Padilla. 2001. Effects of Perkinsus marinus on reproduction and condition of the Eastern oyster, Crassostrea virginica, depend on timing. J. Shellfish Res., 20, 1025-1034.

Dorschel, B., D. Hebbeln, A. Rüggeberg and C. Dullo. 2007. Carbonate budget of a cold-water coral carbonate mound: Propeller Mound, Porcupine Seabight. Int. J. Earth Sci., 96, 73-83.

Duffy, M. A. and S. E. Forde. 2009. Ecological feedbacks and the evolution of resistance. J. Anim. Ecol., 78, 1106-1112.

Elner, R. W. and R. E. Lavoie. 1983. Predation on American oysters (Crassostrea virginica (Gmelin)) by American lobsters (Homarus americanus Milne-Edwards), rock crabs (Cancer irroratus Say), and mud crabs (Neopanope sayi (Smith)). J. Shellfish Res., 3, 129-134.

Fabry, V. J., J. B. McClintock, J. T. Mathis and J. M. Grebmeier. 2009. Ocean acidification at high latitudes: the bellweather. Oceanography, 22, 160-171.

Fegley, S. R., S. E. Ford, J. N. Kraeuter and H. H. Haskin. 2003. The persistence of New Jersey's oyster seedbeds in the presence of oyster disease and harvest: the role of management. J. Shellfish Res., 22, 451-464.

Ford, S. E. 1996. Range extension by the oyster parasite Perkinsus marinus into the northeastern United States: response to climate change. J. Shellfish Res., 15, 45-56.

1997. History and present status of molluscan shellfisheries from Barnegat Bay to Delaware Bay. NOAA Tech. Rpt., NMFS 127, 119-140.

Ford, S. E. and H. H. Haskin. 1982. History and epizootiology of Haplosporidium nelsoni (MSX), an oyster pathogen in Delaware Bay, 1957-1980. J. Invertebr. Pathol., 40, 118-141.

Galtsoff, P. S. 1931. Survey of oyster bottoms in Texas. U.S. Bur. Fish. Invest., Report 6, 30 pp.

Galvani, A. P. and M. Slatkin. 2004. Intense selection in an age-structured population. Proc. R. Soc. Lond. B. Biol. Sci., 271, 171-176. 
Gottlieb, S. J. and M. E. Schweighofer. 1996. Oysters and the Chesapeake Bay ecosystem: a case for exotic species introduction to improve environmental quality? Estuaries, 19, 639-650.

Green, M. A., R. C. Aller and J. Y. Aller. 1998. Influence of carbonate dissolution on survival of shell-bearing meiobenthos in nearshore sediments. Limnol. Oceanogr., 43, 18-28.

Green, M. A., M. E. Jones, C. L. Boudreau, R. L. Moore and B. A. Westman. 2004. Dissolution mortality of juvenile bivalves in coastal marine deposits. Limnol. Oceanogr., 49, 727-734.

Gregalis, K. C., S. P. Powers and K. L. Heck Jr. 2008. Restoration of oyster reefs along a bio-physical gradient in Mobile Bay, Alabama. J. Shellfish Res., 27, 1163-1169.

Gullian, M. and L. Aguirre-Macedo. 2009. Seasonal variation of physiological parameters in the eastern oyster Crassostrea virginica from a tropical region of the Gulf of Mexico. J. Shellfish Res., $28,439-446$.

Gunter, G. 1938. A new oyster clutch [sic] for the Texas coast. Proc. Tex. Acad. Sci., 21, 14.

- 1972. Use of dead reef shell and its relation to estuarine conservation. Trans. N. Am. Wildl. Nat. Resour. Conf., pp. 110-121.

1979. The grit principle and the morphology of oyster reefs. Proc. Natl. Shellfish. Assoc., 69, $1-5$.

Gunter, G., C. E. Dawson and W. J. Demoran. 1957. Determination of how long oysters have been dead by studies of their shells. Proc. Natl. Shellfish. Assoc., 47, 31-33.

Guyondet, T., V. G. Koutitonsky and S. Roy. 2005. Effects of water renewal estimates on the oyster aquaculture potential of an inshore area. J. Mar. Syst., 58, 35-51.

Haltuch, M. A., A. E. Punt and M. W. Dorn. 2008. Evaluating alternative estimators of fishery management reference points. Fish. Res., 94, 290-303.

Harding, J. M., R. Mann, M. J. Southworth and J. A. Wesson. 2010. Management of the Piankatank River, Virginia, in support of oyster (Crassostrea virginica, Gmelin 1791) fishery repletion. J. Shellfish Res., 29, 867-888.

Hargis Jr., W. J. and D. S. Haven. 1994. The precarious state of the Chesapeake public oyster resource. in Toward a sustainable coastal watershed: the Chesapeake experiment. Proceedings of the conference 1-3 June 1994, Norfolk Va., P. Hill and S. Nelson, eds., Chesapeake Research Consortium Publication, No. 149, 559-584.

Hasu, T., D. P. Benesh and E. T. Valtonen. 2009. Differences in parasite susceptibility and costs of resistance between naturally exposed and unexposed host populations. J. Evol. Biol., 22, 699707.

Haven, D. S. and J. P. Whitcomb. 1983. The origin and extent of oyster reefs in the James River, Virginia. J. Shellfish Res., 3, 141-151.

Hayes, P. F. and R. W. Menzel. 1981. The reproductive cycle of early setting Crassostrea virginica (Gmelin) in the northern Gulf of Mexico, and its implications for population recruitment. Biol. Bull. (Woods Hole), 160, 80-88.

Hilborn, R. 2002. The dark side of reference points. Bull. Mar. Sci., 70, 403-408.

Hilborn, R. and C. J. Walters. 1992. Quantitative fisheries stock assessment. Choice, dynamics and uncertainty. New York, Chapman \& Hall, 570 pp.

Hofmann, E. E., J. M. Klinck, E. N. Powell, S. Boyles and M. Ellis. 1994. Modeling oyster populations II. Adult size and reproductive effort. J. Shellfish Res., 13, 165-182.

Hong, W., E. Keppens, P. Nielsen, A. van Riet. 1995. Oxygen and carbon isotope study of the Holocene oyster reefs and paleoenvironmental reconstruction on the northwest coast of Bohai Bay, China. Mar. Geol., 124, 289-302.

Hopkins, S. H. 1954. Oyster setting on the Gulf coast. Proc. Natl. Shellfish. Assoc., 45, 52-55.

— 1956. Notes on the boring sponges in Gulf coast estuaries and their relation to salinity. Bull. Mar. Sci. Gulf Caribb., 6, 44-58. 
1962. Distribution of species of Cliona (boring sponge) on the eastern shore of Virginia in relation to salinity. Chesapeake Sci., 3, 121-124.

Hover, V. C., L. M. Walter and D. R. Peacor. 2001. Early marine diagenesis of biogenic aragonite and Mg-calcite: new constraints from high-resolution STEM and AEM analyses of modern platform carbonates. Chem. Geol., 175, 221-248.

HSRL. 2010. Report of the 2010 Stock Assessment Workshop (12th SAW) for the New Jersey Delaware Bay Oyster Beds. Port Norris, New Jersey, Haskin Shellfish Research Laboratory, Rutgers University, $142 \mathrm{pp}$.

Jackson, J. B. C., M. X. Kirby, W. H. Berger, K. A. Bjorndal, L. W. Botsford, B. J. Bourque, R. H. Bradbury, R. Cooke, J. Erlandson, J. A. Estes, T. P. Hughes, S. Kidwell, C. B. Lange, H. S. Lenihan, J. M. Pandolfi, C. H. Peterson, R. S. Steneck, M. J. Tegner and R. R. Warner. 2001. Historical overfishing and the recent collapse of coastal ecosystems. Science (Wash. D.C.), 293, 629-637.

Jones, A. T., J. M. Kennard, G. A. Logan, E. Grosjean and J. Marshall. 2009. Fluid expulsion features associated with sand waves on Australia's central North West Shelf. Geo-Marine Lett., 29, 233-248.

Jordan, S. J. and J. M. Coakley. 2004. Long-term projections of eastern oyster populations under various management scenarios. J. Shellfish Res., 23, 63-72.

Jordan, S. J., K. N. Greenhawk, C. B. McCollough, J. Vanisko and M. L. Homer. 2002. Oyster biomass, abundance, and harvest in northern Chesapeake Bay: trends and forecasts. J. Shellfish Res., 21, 733-741.

Jumars, P. A. and A. R. M. Nowell. 1984. Fluid and sediment dynamic effects on marine benthic community structure. Am. Zool., 24, 45-55.

Kennedy, V. S. and C. B. Krantz. 1982. Comparative gametogenic and spawning patterns of the oyster Crassostrea virginica (Gmelin) in central Chesapeake Bay. J. Shellfish Res., 2, 133-140.

Kennedy, W. J., J. D. Taylor and A. Hall. 1969. Environmental and biological controls on bivalve shell mineralogy. Biol. Rev. Camb. Philos. Soc., 44, 499-530.

Kidwell, S. M. 2001. Preservation of species abundance in marine death assemblages. Science (Wash. D.C.), 294, 1091-1094.

Kidwell, S. M., T. A. Rothfus and M. M. R. Best. 2001. Sensitivity of taphonomic signature to sample size, sieve size, damage scoring system, and target taxa. Palaios, 16, 26-52.

Kimmel, D. G. and R. I. E. Newell. 2007. The influence of climate variation on eastern oyster (Crassostrea virginica) juvenile abundance in Chesapeake Bay. Limnol. Oceanogr., 52, 959-965.

Kleypas, J. A. and K. K. Yates. 2009. Coral reefs and ocean acidification. Oceanography, 22, 108-117. Kosnik, M. A., Q. Hua, D. S. Kaufman and R. A. Wüst. 2009. Taphonomic bias and time-averaging in tropical molluscan death assemblages: differential shell half-lives in Great Barrier Reef sediment. Paleobiology, 35, 565-586.

Kraeuter, J. N., S. Ford and M. Cummings. 2007. Oyster growth analysis: a comparison of methods. J. Shellfish Res., 26, 479-491.

Launey, S. and D. Hedgecock. 2001. High genetic load in the Pacific oyster Crassostrea gigas. Genetics, 159, 255-265.

Lawrence, D. 1968. Taphonomy and information losses in fossil communities. Geol. Soc. Am. Bull., 79, 1315-1330.

Lazo, D. G. 2004. Bivalve taphonomy: testing the effect of life habits on the shell condition of the littleneck clam Protothaca (Protothaca) staminea (Mollusca: Bivalvia). Palaios, 19, 451-459.

Lenihan, H. S. 1999. Physical-biological coupling on oyster reefs: how habitat structure influences individual performance. Ecol. Monogr., 69, 251-275.

Lescinsky, H. L. 1993. Taphonomy and paleoecology of epibionts on the scallops Chlamys hastata (Sowerby 1843) and Chlamys rubida (Hinds 1845). Palaios, 8, 267-277. 
Lescinsky, H. L., E. Edinger and M. J. Risk. 2002. Mollusc shell encrustation and bioerosion rates in a modern epeiric sea: taphonomy experiments in the Java Sea, Indonesia. Palaios, 17, 171191.

Loosanoff, V. L. 1966. Time and intensity of setting of the oyster Crassostrea virginica, in Long Island Sound. Biol. Bull. (Woods Hole), 130, 211-227.

MacKenzie Jr., C. L. 1977. Development of an aquacultural program for rehabilitation of damaged oyster reefs in Mississippi. Mar. Fish. Rev., 39(8), 1-13.

MacKenzie, K. and S. C. Bishop. 1999. A discrete-time epidemiological model to quantify selection for disease resistance. Anim. Sci., 69, 543-551.

Mackin, J. G. 1959. A method of estimation of mortality rates in oysters. Proc. Natl. Shellfish. Assoc., $50,41-51$.

— 1962. Oyster disease caused by Dermocystidium marinum and other microorganisms in Louisiana. Publ. Inst. Mar. Sci. Univ. Tex., 7, 132-229.

Mackin, J. G. and S. H. Hopkins. 1962. Studies on oyster mortality in relation to natural environments and to oil fields in Louisiana. Publ. Inst. Mar. Sci. Univ. Tex., 7, 1-131.

Mackin, J. G. and A. K. Sparks. 1962. A study of the effect on oysters of crude oil loss from a wild well. Publ. Inst. Mar. Sci. Univ. Tex., 7, 230-261.

Mallela, J. and C. T. Perry. 2007. Calcium carbonate budgets for two coral reefs affected by differential terrestrial runoff regimes, Rio Bueno, Jamaica. Coral Reefs, 26, 129-145.

Mann, R. 2000. Restoring the oyster reef communities in the Chesapeake Bay: a commentary. J. Shellfish Res., 19, 335-339.

Mann, R. and D. A. Evans. 1998. Estimation of oyster, Crassostrea virginica, standing stock, larval production and advective loss in relation to observed recruitment in the James River, Virginia. J. Shellfish Res., 17, 239-253.

Mann, R., J. M. Harding and M. J. Southworth. 2009. Reconstructing pre-colonial oyster demographics in the Chesapeake Bay, USA. Estuar. Coast. Shelf Sci., 85, 217-222.

Mann, R. and E. N. Powell. 2007. Why oyster restoration goals in the Chesapeake Bay are not and probably cannot be achieved. J. Shellfish Res., 26, 905-917.

Marshall, N. 1954. Changes in the physiography of oyster bars in the James River, Virginia. Natl. Shellfish. Assoc. Conv. Add., pp. 113-121.

Martinius, A. W. 1991. Growth rates and population dynamics in Crassostrea cf. rarilamella from the Lower Eocene Roda Formation (southern Pyrenees, Spain). Geol Mijnbouw, 70, 59-73.

Maunder, M. N. 2003. Is it time to discard the Schaefer model from the stock assessment scientist's toolbox. Fish. Res., 61, 145-149.

Meadows, P. S. and A. Meadows. 1991. The geotechnical and geochemical implications of bioturbation in marine sedimentary ecosystems. Symp. Zool. Soc. Lond., 63, 157-181.

Meyer, D. L. and E. C. Townsend. 2000. Faunal utilization of created intertidal Eastern oyster (Crassostrea virginica) reefs in the southeastern United States. Estuaries, 23, 34-45.

Miller, A. W., A. C. Reynolds, C. Sobrino and G. F. Riedel. 2009. Shellfish face uncertain future in high $\mathrm{CO}_{2}$ world: influence of acidification on oyster larvae calcification and growth in estuaries. Plos One, 4(5), e5661, doi:10.1371/journal.pone.0005661.

Moore, H. F. 1907. Survey of oyster bottoms in Matagorda Bay, Texas. U.S. Bur. Fish. Doc., 610, $1-86$.

1911. Condition and extent of the natural oyster beds of Delaware. U.S. Bur. Fish. Doc., 745, $1-29$.

Nell, J. A., I. R. Smith and A. K. Sheridan. 1999. Third generation evaluation of Sydney rock oyster Saccostrea commercialis (Iredale and Roughley) breeding lines. Aquaculture, 170, 195203. 
Newell, R. I. E. and E. W. Koch. 2004. Modeling seagrass density and distribution in response to changes in turbidity stemming from bivalve filtration and seagrass sediment stabilization. Estuaries, 27, 793-806.

Notaro, M., W-C. Wang and W. Gong. 2006. Model and observational analysis of the northeast U.S. regional climate and its relationship to the PNA and NAO patterns during early winter. Mon. Weather Rev., 134, 3479-3505.

Olsen, L. A., S. Johnston Jr., D. Mades, D. Lee, G. Molinaro and C. Listowski. 2006. Relocation of oysters from Phillippi Creek (Sarasota, Florida) to a nearby section of the intracoastal waterway to create new reefs. Fl. Sci., 69, 80-91.

Olszewski, T. F. 2004. Modeling the influence of taphonomic destruction, reworking, and burial on time-averaging in fossil accumulations. Palaios, 19, 39-50.

Parras, A. and S. Casadío. 2006. The oyster Crassostrea? hatcheri (Ortmann, 1897), a physical ecosystem engineer from the Upper Oligocene-Lower Miocene of Patagonia, southern Argentina. Palaios, 21, 168-186.

Parsons-Hubbard, K. 2005. Molluscan taphofacies in recent carbonate reef/lagoon systems and their application to sub-fossil samples from reef cores. Palaios, 20, 175-191.

Paynter, K. T. 1996. The effects of Perkinsus marinus infection on physiological processes in the Eastern oyster, Crassostrea virginica. J. Shellfish Res., 15, 119-125.

Perry, C. T. and S. G. Smithers. 2006. Taphonomic signatures of turbid-zone reef development: examples from Paluma Shoals and Lugger Shoal, inshore central Great Barrier Reef, Australia. Palaeogeogr. Palaeoclimatol. Palaeoecol., 242, 1-20.

Perry, C. T. and K. G. Taylor. 2006. Inhibition of dissolution within shallow water carbonate sediments: impacts of terrigenous sediment input on syn-depositional carbonate diagenesis. Sedimentology, 53, 495-513.

Peterson, C. H. 1976. Relative abundances of living and dead molluscs in two California lagoons. Lethaia, 9, 137-148.

Peterson, C. H., H. C. Summerson and P. B. Duncan. 1984. The influence of seagrass cover on population structure and individual growth rate of a suspension-feeding bivalve, Mercenaria mercenaria. J. Mar. Res., 42, 123-138.

Powell, E. N. 1992. A model for death assemblage formation. Can sediment shelliness be explained? J. Mar. Res., 50, 229-265.

Powell, E. N. and K. A. Ashton-Alcox. 2004. A comparison between a suction dredge and a traditional oyster dredge in the transplantation of oysters in Delaware Bay. J. Shellfish Res., 23, 803823.

Powell, E. N., K. A. Ashton-Alcox, S. E. Banta and A. J. Bonner. 2001. Impact of repeated dredging on a Delaware Bay oyster reef. J. Shellfish Res., 20, 961-975.

Powell, E. N., K. A. Ashton-Alcox, J. A. Dobarro, M. Cummings and S. E. Banta. 2002. The inherent efficiency of oyster dredges in survey mode. J. Shellfish Res., 21, 691-695.

Powell, E. N., K. A. Ashton-Alcox and J. N. Kraeuter. 2007. Reevaluation of eastern oyster dredge efficiency in survey mode: Application in stock assessment. N. Am. J. Fish. Manage., 27, 492511.

Powell, E. N., K. A. Ashton-Alcox, J. N. Kraeuter, S. E. Ford and D. Bushek. 2008a. Long-term trends in oyster population dynamics in Delaware Bay: Regime shifts and response to disease. J. Shellfish Res., 27, 729-755.

Powell, E. N., C. E. Brett, K. M. Parsons-Hubbard, W. R. Callender, G. M. Staff, S. E. Walker, A. Raymond and K. A. Ashton-Alcox. 2011b. The relationship of bionts and taphonomic processes in molluscan taphofacies formation on the continental shelf and slope: eight-year trends - Gulf of Mexico and Bahamas. Facies, 57, 15-37. 
Powell, E. N., W. R. Callender, G. M. Staff, K. M Parsons-Hubbard, C. E. Brett, S. E. Walker, A. Raymond and K. A. Ashton-Alcox. 2008b. Mollusc shell condition after eight years on the sea floor - taphonomy in the Gulf of Mexico and Bahamas. J. Shellfish Res., 27, 191-225.

Powell, E. N. and D. J. Davies. 1990. When is an "old" shell really old? J. Geol., 98, 823-844.

Powell, E. N., J. D. Gauthier, E. A. Wilson, A. Nelson, R. R. Fay and J. M. Brooks. 1992. Oyster disease and climate change. Are yearly changes in Perkinsus marinus parasitism in oysters (Crassostrea virginica) controlled by climatic cycles in the Gulf of Mexico? P.S.Z.N.I.: Mar. Ecol., 13, 243-270.

Powell, E. N., J. J. Gendek and K. A. Ashton-Alcox. 2005. Fisherman choice and incidental catch: size frequency of oyster landings in the New Jersey oyster fishery. J. Shellfish Res., 24, 469-476.

Powell, E. N. and J. M. Klinck. 2007. Is oyster shell a sustainable estuarine resource? J. Shellfish Res., 26, 181-194.

Powell, E. N., J. M. Klinck, K. A. Ashton-Alcox and J. N. Kraeuter. 2009a. Multiple stable reference points in oyster populations: biological relationships for the eastern oyster (Crassostrea virginica) in Delaware Bay. Fish. Bull., 107, 109-132.

2009b. Multiple stable reference points in oyster populations: implications for reference pointbased management. Fish. Bull., 107, 133-147.

Powell, E. N., J. M. Klinck, X. Guo, E. E. Hofmann, S. E. Ford and D. Bushek. 2011c. Can oysters Crassostrea virginica develop resistance to Dermo disease in the field: evaluation using a genebased population dynamics model. J. Shellfish Res., 30, 685-712.

Powell, E. N., J. M. Klinck, X. Guo, E. E. Hofmann, S. E. Ford and D. Bushek. 2012. Can oysters Crassostrea virginica develop resistance to Dermo disease in the field: the impediment posed by climate cycles. J. Mar. Res., 70, 309-355.

Powell, E. N., J. M. Klinck and E. E. Hofmann. 1996. Modeling diseased oyster populations. II. Triggering mechanisms for Perkinsus marinus epizootics. J. Shellfish Res., 15, 141-165.

2011a. Generation time and the stability of sex-determining alleles in oyster populations as deduced using a gene-based population dynamics model. J. Theor. Biol., 271, 27-43.

Powell, E. N., J. M. Klinck, E. E. Hofmann, E. A. Wilson-Ormond and M. S. Ellis. 1995b. Modeling oyster populations. V. Declining phytoplankton stocks and the population dynamics of American oyster (Crassostrea virginica) populations. Fish. Res., 24, 199-222.

Powell, E. N., J. N. Kraeuter and K. A. Ashton-Alcox. 2006. How long does oyster shell last on an oyster reef? Estuar. Coast. Shelf Sci., 69, 531-542.

Powell, E. N., J. Song, M. S. Ellis and E. A. Wilson-Ormond. 1995a. The status and long-term trends of oyster reefs in Galveston Bay, Texas. J. Shellfish Res., 14, 439-457.

Powell, E. N., G. M. Staff, W. R. Callender, K. A. Ashton-Alcox, C. E. Brett, K. M. Parsons-Hubbard, S. E. Walker and A. Raymond. 2011d. Taphonomic degradation of molluscan remains during thirteen years on the continental shelf and slope of the northwestern Gulf of Mexico. Palaeogeogr. Palaeoclimatol. Palaeoecol., 312, 209-232.

Powell, E. N., G. M. Staff, D. J. Davies and W. R. Callender. 1989. Macrobenthic death assemblages in modern marine environments: formation, interpretation and application. Crit. Rev. Aquat. Sci., 1:555-589.

Powell, E. N., M. E. White, E. A. Wilson and S. M. Ray. 1987a. Small-scale spatial distribution of a pyramidellid snail ectoparasitic, Boonea impressa, in relation to its host, Crassostrea virginica, on oyster reefs. P.S.Z.N.I.: Mar. Ecol., 8, 107-130.

1987b. Small-scale spatial distribution of oysters (Crassostrea virginica) on oyster reefs. Bull. Mar. Sci., 41, 835-855.

Power, A., B. Corley, D. Atkinson, R. Walker, D. Harris, J. Manley and T. Johnson. 2010. A caution against interpreting and quantifying oyster habitat loss from historical surveys. J. Shellfish Res., 29, 927-936. 
Precht, E. and M. Huettel. 2004. Rapid wave-driven advective pore water exchange in a permeable coastal sediment. J. Sea Res., 51, 93-107.

Pufahl, P. K. and N. P. James. 2006. Monospecific Pliocene oyster buildups, Murray Basin, South Australia: brackish water end member of the reef spectrum. Palaeogeogr. Palaeoclimatol. Palaeoecol., 233, 11-33.

Ragone Calvo, L. M., R. L. Wetzel and E. M. Burreson. 2001. Development and verification of a model for the population dynamics of the protistan parasite, Perkinsus marinus, within its host, the eastern oyster, Crassostrea virginica, in Chesapeake Bay. J. Shellfish Res., 20, 231-241.

Ray, S. M. 1996. Historical perspective on Perkinsus marinus disease of oysters in the Gulf of Mexico. J. Shellfish Res., 15, 9-11.

Restrepo, V. R., G. G. Thompson, P. M. Mace, W. K. Gabriel, L. L. Low, A. D. MacCall, R. D. Methot, J. E. Powers, B. L. Taylor, P. R. Wade and J. F. Witzig. 1998. Technical guidance on the use of precautionary approaches to implementing National Standard 1 of the Magnuson/Stevens Fishery Conservation and Management Act. NOAA Tech. Mem., NMFS-F/SPO-31, 54 pp.

Rodney, W. S. and K. T. Paynter. 2006. Comparisons of macrofaunal assemblages on restored and non-restored oyster reefs in mesohaline regions of Chesapeake Bay in Maryland. J. Exp. Mar. Biol. Ecol., 335, 39-51.

Rosenberg, G. D. 1980. The "vital effect" on skeletal trace element content as exemplified by magnesium, in Skeletal biomineralization: patterns, processes and evolutionary trends, J. G. Carter, ed., vol. 1, chap. 23, pp. 567-577.

Rothschild, B. J., J. S. Ault, P. Goulletquer and M. Héral. 1994. Decline of the Chesapeake Bay oyster populations: a century of habitat destruction and overfishing. Mar. Ecol. Prog. Ser., 111, 29-39.

Royer, J., M. Ropert, M. Mathieu and K. Costil. 2006. Presence of spionid worms and other epibionts in Pacific oysters (Crassostrea gigas) cultured in Normandy, France. Aquaculture, 253, 461-474.

Sartoretto, S. 1998. Bioérosion des concrétions coralligères de Méditerranée par les organismes perforants: essai de quantification des processus. C.R. Acad. Sci. Paris Sci. Terre Planétes, 327, 831-844.

Smith, G. F., D. G. Bruce, E. B. Roach, A. Hansen, R. I. E. Newell and A. M. McManus. 2005. Assessment of recent habitat conditions of eastern oyster Crassostrea virginica bars in mesohaline Chesapeake Bay. N. Am. J. Fish. Manage., 25, 1569-1590.

Smith, G. F., K. N. Greenhawk, D. G. Bruce, E. B. Roach and S. J. Jordan. 2001. A digital presentation of the Maryland oyster habitat and associated bottom types in the Chesapeake Bay (1974-1983). J. Shellfish Res., 20, 197-206.

Soniat, T. M., B. C. Broadhurst III and E. L. Haywood III. 1991. Alternatives to clam shell as cultch for oysters and the use of gypsum for the production of cultchless oysters. J. Shellfish Res., 10, 405-410.

Soniat, T. M., E. E. Hofmann, J. M. Klinck and E. N. Powell. 2009. Differential modulation of eastern oyster (Crassostrea virginica) disease parasites by the El Niño-Southern Oscillation and the North Atlantic Oscillation. Int. J. Earth Sci., 98, 99-114.

Soniat, T. M., J. M. Klinck, E. N. Powell and E. E. Hofmann. 2006. Understanding the success and failure of oyster populations: climatic cycles and Perkinsus marinus. J. Shellfish Res., 25, 83-93.

Southworth, M., J. M. Harding, J. A. Wesson and R. Mann. 2010. Oyster (Crassostrea virginica, Gmelin 1791) population dynamics on public reefs in the Great Wicomico River, Virginia, USA. J. Shellfish Res., 29, 271-290.

Southworth, M. and R. Mann. 1998. Oyster reef broodstock enhancement in the Great Wicomico River, Virginia. J. Shellfish Res., 17, 1101-1114.

- 2004. Decadal scale changes in seasonal patterns of oyster recruitment in the Virginia sub estuaries of the Chesapeake Bay. J. Shellfish Res., 23, 391-402. 
Staff, G. M. and E. N. Powell. 1990. Taphonomic signature and the imprint of taphonomic history: discriminating between taphofacies of the inner continental shelf and a microtidal inlet, in Paleocommunity temporal dynamics: the long-term development of multispecies assemblages, W. Miller III, ed., Spec. Publ. (Paleontol. Soc.), 5, 370-390.

Stauber, L. A. 1950. The problem of physiological species with special reference to oysters and oyster drills. Ecology, 31, 109-118.

Stiner, J. L. and L. J. Walters. 2008. Effects of recreational boating on oyster reef architecture and species interactions. Fl. Sci., 71, 31-44.

Strayer, D. L. and H. M. Malcom. 2007. Shell decay rates of native and alien freshwater bivalves and implications for habitat engineering. Freshwater Biol., 52, 1611-1617.

Tamburri, M. N., M. W. Luckenbach, D. L. Breitburg and S. M. Bonniwell. 2008. Settlement of Crassostrea ariakensis larvae: effects of substrate, biofilms, sediment and adult chemical cues. J. Shellfish Res., 27, 601-608.

Taylor, J. and D. Bushek. 2008. Intertidal oyster reefs can persist and function in a temperate North American Atlantic estuary. Mar. Ecol. Prog. Ser., 361, 301-306.

Taylor, J. D. and M. Layman. 1972. The mechanical properties of bivalve (Mollusca) shell structures. Palaeontology (Lond.), 15, 73-87.

Thatje, S., O. Heilmayer and J. Laudien. 2008. Climate variability and El Niño Southern Oscillation: implications for natural coastal resources and management. Helgol. Mar. Res., 62 (Suppl. 1), S5S14.

Tolan, J. M. 2007. El Niño-Southern Oscillation impacts translated to the watershed scale: estuarine salinity patterns along the Texas Gulf coast, 1982 to 2004. Estuar. Coast. Shelf Sci., 72, 247-260.

Tomašových, A., F. T. Fürsich and T. D. Olszewski. 2006. Modeling shelliness and alteration in shell beds: variation in hardpart input and burial rates leads to opposing predictions. Paleobiology, 32, 278-298.

Tribble, G. W. 1993. Organic matter oxidation and aragonite diagenesis in a coral reef. J. Sediment. Petrol., 63, 523-527.

Tribble, G. W., F. J. Sansone, R. W. Buddemeier and Y. H. Li. 1992. Hydraulic exchange between a coral reef and surface sea water. Geol. Soc. Am. Bull., 104, 1280-1291.

Twichell, D., L. Edmiston, B. Andrews, W. Stevenson, J. Donoghue, R. Poore and L. Osterman. 2010. Geologic controls on the recent evolution of oyster reefs in Apalachicola Bay and St. George Sound, Florida. Estuar. Coast. Shelf Sci., 88, 385-394.

Villiers, S. de. 2005. Foraminiferal shell-weight evidence for sedimentary calcite dissolution above the lysocline. Deep. Sea Res. I, 52, 671-680.

Waldbusser, G. G., R. A. Steenson and M. A. Green. 2011. Oyster shell dissolution rates in estuarine waters: effects of $\mathrm{pH}$ and shell legacy. J. Shellfish Res., 30, 659-669.

Walker, S. E and S. T. Goldstein. 1999. Taphonomic tiering: experimental field taphonomy of molluscs and foraminifera above and below the sediment water interface. Palaeogeogr. Palaeoclimatol. Palaeoecol., 149, 227-244.

Walter, L. M. and E. A. Burton. 1990. Dissolution of recent platform carbonate sediments in marine pore fluids. Am. J. Sci., 290, 601-645.

Wang, Y. and X. Guo. 2007. Development and characterization of EST-SSR markers in the eastern oyster Crassostrea virginica. Mar. Biotechnol., 9, 500-511.

Wang, Y., Z. Xu, J. C. Pierce and X. Guo. 2005. Characterization of eastern oyster (Crassostrea virginica $\mathrm{Gmelin}$ ) chromosomes by fluorescence in situ hybridization with bacteriophage $\mathrm{P} 1$ clones. Mar. Biotechnol., 7, 207-214.

Wang, Z. P., X. M. Guo, S. K. Allen Jr. and R. Wang. 1999. Aneuploid Pacific oyster (Crassostrea gigas Thunberg) as incidentals from triploid production. Aquaculture, 173, 347-357. 
Warburton, F. E. 1958. Control of the boring sponge on oyster beds. Fish. Res. Bd. Canada Prog. Rep. Atl. Coast. Stns., 69, 7-11.

Wilber, D. H. 1992. Associations between freshwater inflows and oyster productivity in Apalachicola Bay, Florida. Estuar. Coast. Shelf Sci., 35, 179-190.

Wilhoit, L. R. 1991. Modelling the population dynamics of different aphid genotypes in plant variety mixtures. Ecol. Modelling, 55, 257-283.

Wilson, E. A., M. E. White, E. N. Powell and S. M. Ray. 1988. Patch formation by the ectoparasitic snail, Boonea impressa, on its oyster host, Crassostrea virginica. Veliger, 31, 101-110.

Wilson-Ormond, E. A., E. N. Powell and S. M. Ray. 1997. Short-term and small-scale variation in food availability to natural oyster populations: food, flow and flux. P.S.Z.N.I. Mar. Ecol., 18, 1-34.

Wisshak, M., M. Gektidis, A. Freiwald and T. Lundälv. 2005. Bioerosion along a bathymetric gradient in a cold-temperate setting (Kosterfjord, SW Sweden): an experimental study. Facies, 51, 93-117.

Woods, H., W. J. Hargis Jr., C. H. Hershner and P. Mason. 2005. Disappearance of the natural emergent 3-dimensional oyster reef system of the James River, Virginia, 1871-1948. J. Shellfish Res., 24, 139-142.

Wootton, J. T., C. A. Pfister and J. D. Forester. 2008. Dynamic patterns and ecological impacts of declining ocean $\mathrm{pH}$ in a high-resolution multi-year dataset. P. Natl. Acad. Sci. USA, 105, 1884818853.

Yoon, H., S. Park, K. Lee and J. Park. 2004. Oyster shell as substitute for aggregate in mortar. Waste Manage. Res., 22, 158-170.

Zbinden, M., C. R. Haag and D. Ebert. 2008. Experimental evolution of field populations of Daphnia magna in response to parasite treatment. J. Evol. Biol., 21, 1068-1078.

Zuschin, M., M. Stachowitsch and R. J. Stanton Jr. 2003. Patterns and processes of shell fragmentation in modern and ancient marine environments. Earth Sci. Rev., 63, 33-82.

Received: 11 November, 2011; revised: 12 March, 2012. 